\title{
EFEITO IN VITRO DE Saccharomyces cerevisiae SOBRE Guignardia citricarpa, AGENTE CAUSAL DA PINTA PRETA DOS CITROS
}

\author{
MAURÍ́CIO BATISTA FiaLHO
}

Dissertação apresentada à Escola Superior de Agricultura "Luiz de Queiroz", Universidade de São Paulo, para obtenção do título de Mestre em Agronomia, Área de Concentração: Microbiologia Agrícola.

PIRACICABA

Estado de São Paulo - Brasil

Dezembro - 2004 


\title{
EFEITO IN VITRO DE Saccharomyces cerevisiae SOBRE Guignardia citricarpa, AGENTE CAUSAL DA PINTA PRETA DOS CITROS
}

\author{
MAURÍCIO BATISTA FIALHO \\ Bacharel e Licenciado em Ciências Biológicas
}

Orientador: Prof. Dr. SÉRGIO FLORENTINO PASCHOLATI

Dissertação apresentada à Escola Superior de Agricultura "Luiz de Queiroz", Universidade de São Paulo, para obtenção do título de Mestre em Agronomia, Área de Concentração: Microbiologia Agrícola.

\author{
PIRACICABA \\ Estado de São Paulo - Brasil \\ Dezembro - 2004
}




\section{Dados Internacionais de Catalogação na Publicação (CIP) DIVISÃO DE BIBLIOTECA E DOCUMENTAÇÃO - ESALQ/USP}

Fialho, Maurício Batista

Efeito in vitro de Saccharomyces cerevisiae sobre Guignardia citricarpa, agente causal da pinta preta dos citros / Maurício Batista Fialho. - - Piracicaba, 2004.

60 p. : il.

Dissertação (Mestrado) - - Escola Superior de Agricultura Luiz de Queiroz, 2004.

Bibliografia.

1. Antagonista 2. Controle biológico 3. Fungo fitopatogênico 4. Laranja 5. Levedura

6. Mancha-preta-dos-citros 7. Patógeno I. Título

CDD 664.80431

"Permitida a cópia total ou parcial deste documento, desde que citada a fonte - O autor" 


\section{AGRADECIMENTOS}

Ao Prof. Dr. Sérgio Florentino Pascholati pela oportunidade e pela orientação conduzida.

Em especial às minhas amigas, as quais eu considero como irmãs Nivea Maria Tonucci e Solange Maria Bonaldo pelo carinho, incentivo e amizade incondicional.

Aos amigos do laboratório de Fisiologia e Bioquímica do Parasitismo André, Leonardo Cavalcante, Leonardo Toffano, Maria Cristina, Marizete, Odair, Patrícia e Robson pelas sugestões e pelo convívio alegre e descontraído.

Aos amigos e amigas Analy, Adriana, Alessandra, Ana Paula, Daniele, Karina, Luis Fernando, Márcia, Milena, Miriam, Rachel, Renata e Vanessa pelos bons momentos compartilhados.

Ao Nelson A. Wulff pelas sugestões na condução do projeto $X$. fastidiosa.

Aos funcionários Carmen, Fernanda, Giovana, Jeferson, Marina, Rodolfo, Sarah e Silvia pela amizade e boa disposição em ajudar.

Aos meus pais João e Maria e irmãs Sandra e Zulmira por todo apoio que tive nesta caminhada.

A todos amigos e colegas que não mencionei, mas que com certeza foram essenciais e contribuíram de forma direta ou indireta para a realização deste trabalho.

Ao CNPq pelo apoio financeiro. 


\section{SUMÁRIO}

Página

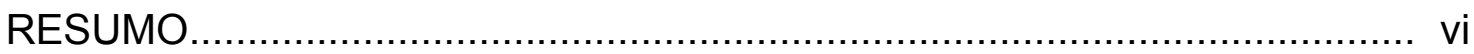

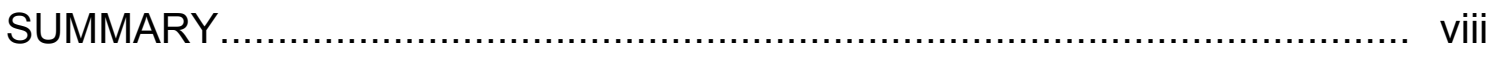

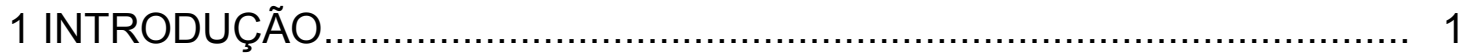

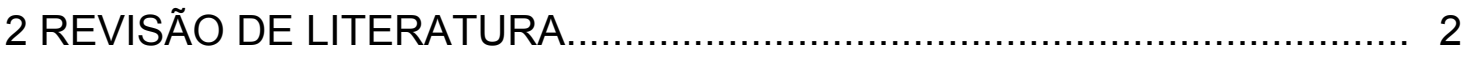

2.1 Pinta preta dos citros............................................................................ 2

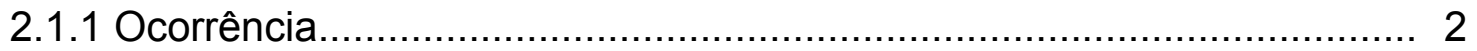

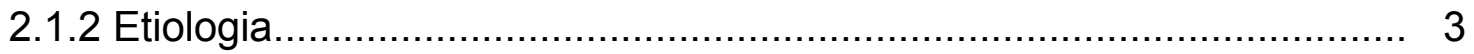

2.1.3 Sintomatologia e Epidemiologia........................................................ 4

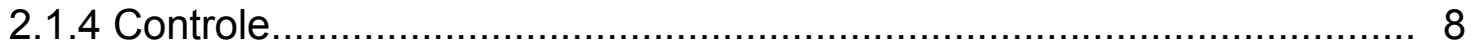

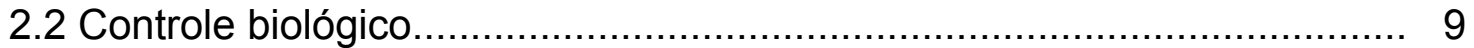

2.2.1 Utilização de fungos e leveduras como agentes de biocontrole............ 11

2.2.1.1 Micoparasitismo....................................................................... 14

2.2.1.2 Produção de antibióticos........................................................ 15

2.2.1.3 Produção de enzimas extracelulares............................................. 16

2.2.1.4 Ação sobre fatores de patogenicidade............................................ 18

2.2.1.5 Competição por nutrientes e nichos de colonização.......................... 18

2.2.1.6 Indução de resistência no hospedeiro.......................................... 19

2.2.2 Saccharomyces cerevisiae e controle biológico................................. 20

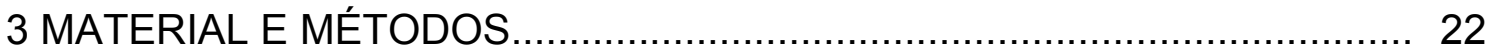

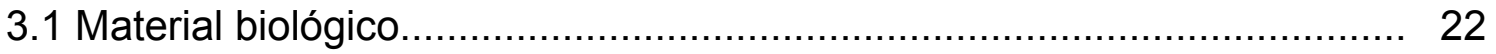

3.1.1 Fungo fitopatogênico............................................................ 22

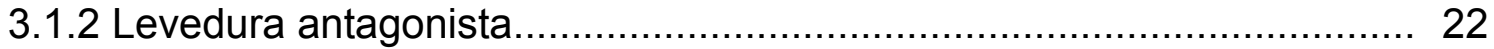


3.2 Meios de cultura e condições de cultivo............................................. 23

3.3 Seleção de linhagens de S. cerevisiae antagônicas a G. citricarpa.......... 23

3.4 Produção de compostos voláteis....................................................... 24

3.5 Obtenção do filtrado de cultura, filtrado de cultura autoclavado e da

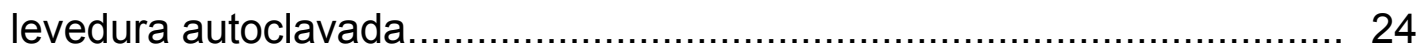

3.6 Efeito do filtrado de cultura, filtrado de cultura autoclavado e da levedura autoclavada sobre o crescimento micelial de G. citricarpa...................... 25

3.7 Produção de enzimas hidrolíticas......................................................... 25

3.7.1 Obtenção da preparação de parede celular (PPC) …......................... 26

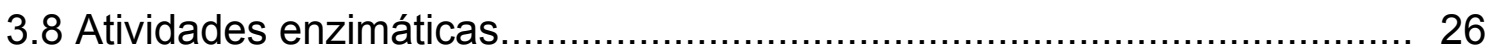

3.8.1 Determinação de açúcares redutores.............................................. 26

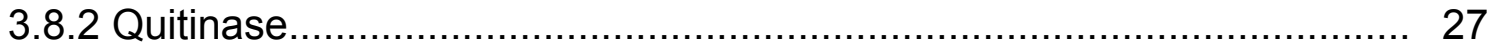

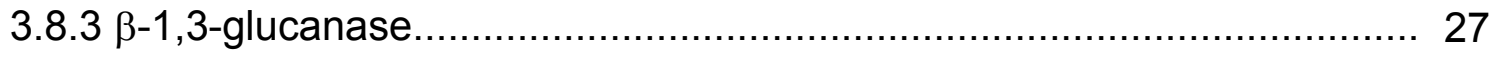

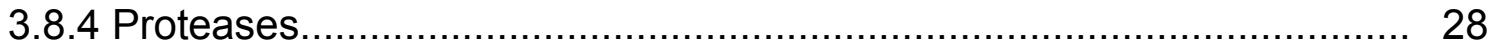

4 RESULTADOS

4.1 Seleção de linhagens de S. cerevisiae antagônicas a G. citricarpa.......... 29

4.2 Produção de compostos voláteis..................................................... 30

4.3 Efeito do filtrado de cultura, filtrado de cultura autoclavado e da levedura autoclavada sobre o crescimento micelial de G. citricarpa...................... 33

4.4 Produção de enzimas hidrolíticas......................................................... 34

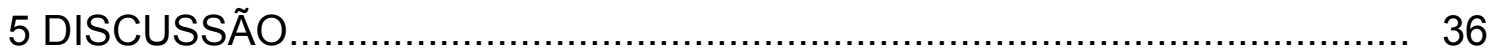

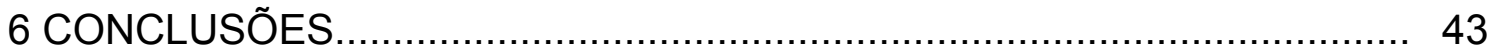

REFERÊNCIAS BIBLIOGRÁFICAS........................................................... 44 


\title{
EFEITO IN VITRO DE Saccharomyces cerevisiae SOBRE Guignardia citricarpa, AGENTE CAUSAL DA PINTA PRETA DOS CITROS
}

\author{
Autor: MAURÍCIO BATISTA FIALHO \\ Orientador: Prof. Dr. SÉRGIO FLORENTINO PASCHOLATI
}

\section{RESUMO}

Devido à percepção dos consumidores sobre o impacto da utilização de pesticidas sobre o ambiente e saúde humana, além da aquisição de resistência por parte dos fitopatógenos, a sociedade tem exercido pressões que levaram ao estabelecimento de políticas governamentais que restringem a utilização de fungicidas levando agricultores e pesquisadores a considerar a aplicação de técnicas de controle biológico de fitopatógenos fúngicos. Guignardia citricarpa é o agente causal da pinta preta dos citros, que é de grande importância econômica, pois interfere na produção e causa depreciação estética dos frutos, acarretando em prejuízos principalmente na comercialização de frutos in natura para o mercado externo. Neste contexto, o objetivo deste trabalho foi a avaliação in vitro do potencial de linhagens de Saccharomyces cerevisiae, utilizadas em processos fermentativos, como agentes de biocontrole contra G. citricarpa. Através de ensaio em placa, foi evidenciado que entre as linhagens de $S$. cerevisiae testadas (BG-1, CR-1, CAT-1, KD-1, K-1 e PE-2), a CR-1 demonstrou a maior atividade antagônica contra o fitopatógeno, causando 
$73 \%$ de inibição do crescimento micelial. Também foi demonstrado que as linhagens são capazes de produzir voláteis de ação fungistática inibindo em até $83 \%$ o desenvolvimento do patógeno. O filtrado de cultura autoclavado e não autoclavado, bem como as células inativadas termicamente, obtidas a partir do crescimento da linhagem CR-1 por $24 \mathrm{~h}$ em meio YEPD, não causaram redução do crescimento vegetativo do fungo. A produção de enzimas hidrolíticas extracelulares (quitinases, $\beta-1,3$-glucanases e proteases) pela levedura não foi detectada em meio YEPD contendo glicose ou preparação de parede celular de G. citricarpa, nos tempos de cultivo avaliados. Baseado nas informações obtidas, foi possível constatar que as linhagens de S. cerevisiae, em especial a linhagem CR-1, são potenciais antagonistas para o controle de G. citricarpa. O possível mecanismo utilizado para inibição pela levedura é a produção de voláteis, no entanto, outros mecanismos não podem ser descartados. Desta forma, o presente trabalho mostra o potencial de $S$. cerevisiae no controle de G. citricarpa em frutos de laranja na pós-colheita. 


\title{
IN VITRO EFFECT OF Saccharomyces cerevisiae ON Guignardia citricarpa, CAUSAL AGENT OF CITRUS BLACK SPOT
}

\author{
Author: MAURÍCIO BATISTA FIALHO \\ Adviser: Prof. Dr. SÉRGIO FLORENTINO PASCHOLATI
}

SUMMARY

Due to the consumers perception about the impact caused by pesticides utilization over the environment and human health, besides the acquisition of resistance for part of the phytopathogens, the society has exercised pressures that had led to the establishment of governmental politics that restrict the use of fungicides leading agriculturists and researchers to consider the application of techniques of biological control of plant pathogenic fungi. Guignardia citricarpa is the causal agent of citrus black spot that has a great economic importance, therefore interfering in production and causing aesthetic depreciation of the fruits that can interfere with commercialization of fresh-fruit in the external market. In this context, the aim of this work was to evaluate in vitro the potential of Saccharomyces cerevisiae strains, used in fermentative process, as biocontrol agents against $G$. citricarpa. Through plate assay it was evidenced that among the tested strains of $S$. cerevisiae (BG-1, CR-1, CAT-1, KD-1, K-1 and PE-2), the strain CR-1 was the one that demonstrated the greatest antagonic activity against the phytopathogen, 
causing $73 \%$ of micelial growth inhibition. It was also demonstrated that the strains were able to produce volatile compounds with fungistatic action inhibiting up to $83 \%$ the development of the pathogen. The autoclaved and not autoclaved culture filtrate, as well as the termical inactivated cell obtained from the growth of strain CR-1 in YEPD medium for $24 \mathrm{~h}$, did not cause reduction in the fungal vegetative growth. The production of extracellular hydrolytic enzymes (chitinases, $\beta-1,3$-glucanases and proteases) by the yeast was not detected in YEPD medium with glucose or cell wall preparation of $G$. citricarpa at the evaluated times. Based upon the obtained information it was possible to evidence that the strains of $S$. cerevisiae, specially the strain CR-1, are potentials antagonists for the control of G. citricarpa. The possible mechanism used for inhibition by yeast is the volatile production, however other mechanisms cannot be discarded. Thus, the present work shows the potential of $S$. cerevisiae to control G. citricarpa in orange fruits in postharvest. 


\section{INTRODUÇÃO}

Alguns dos problemas associados à utilização de agrotóxicos incluem freqüentes falhas no controle, devido à aquisição de resistência por parte dos fitopatógenos, contaminação ambiental e danos à saúde dos seres humanos. Devido a estas preocupações e a pressões exercidas pela sociedade, houve um incentivo para que pesquisadores e produtores buscassem novos caminhos para o controle de doenças nas mais diferentes culturas (Gullino \& Kuijpers, 1994; Ragsdale \& Sisler, 1994).

A utilização de fungos e leveduras para o biocontrole de doenças pode interromper algum estágio da doença ou do ciclo de vida do patógeno através de diversos mecanismos tais como parasitismo, produção de antibióticos e enzimas hidrolíticas, e competição por nutrientes e nichos de colonização. A prevenção da infecção, redução na colonização, diminuição da esporulação ou da sobrevivência do patógeno podem proporcionar diferentes níveis de controle através da utilização de microrganismos antagônicos (Punja \& Utkhede, 2003).

Em virtude de prejuízos causados por Guignardia citricarpa, agente causal da pinta preta dos citros, na comercialização de frutos in natura, principalmente no mercado externo, e ao crescente interesse pela utilização de métodos não agressivos ao ambiente, ou que ao menos reduzam a utilização de fungicidas no controle da doença, este trabalho objetivou avaliar a capacidade de linhagens da levedura Saccharomyces cerevisiae, utilizadas na fermentação alcoólica, em controlar o desenvolvimento in vitro de G. citricarpa, bem como visou elucidar os seus possíveis mecanismos de ação. 


\section{REVISÃO DE LITERATURA}

\subsection{Pinta preta dos citros}

\subsubsection{Ocorrência}

A pinta preta dos citros ou mancha preta dos citros é uma doença que afeta todas as espécies de Citrus com exceção da laranja azeda (C. aurantium L.) e seus híbridos que não apresentam susceptibilidade. Os limoeiros também são susceptíveis e podem ocorrer consideráveis prejuízos em laranja doce (C. sinenses) e pomelo (C. paradisi Macf.) (Kotzé, 1981; Kotzé 1996). O fungo pode estar na área do pomar e a doença pode demorar de 5 a 30 anos para se manifestar e espalhar de forma epidêmica (Kotzé, 1981; Kotzé 1996).

A pinta preta foi inicialmente descrita na Austrália nas proximidades da cidade de Sidney no ano de 1895, sendo responsável por grandes perdas com relação a frutos de laranjeira da variedade Valência (Kiely, 1948). Em 1925, foi constatada na província de Natal, na África do Sul (Doidge, 1929). Nos anos posteriores, ela foi detectada em diversos continentes como Ásia (China, Filipinas, Indonésia, Taiwan e Japão), África (Swazilandia, Zimbabwe e Moçambique) e América do Sul (Argentina, Peru e Brasil) (Kotzé, 1988; Feichtenberger, 1996; Feichtenberger et al., 1997).

No território brasileiro, a pinta preta foi descrita em 1980 (Robbs et al., 1980), afetando pomares em São Gonçalo e Itaboraí, no Estado do Rio de Janeiro. Posteriormente disseminou-se pela Baixada Costeira Fluminense (Robbs, 1990; Robbs \& Bittencourt, 1995). Em 1986, a doença foi identificada 
na principal região produtora do Rio Grande do Sul, no Vale do Caí (Feichtenberger, 1996).

O primeiro relato referente à pinta preta no Estado de São Paulo foi feito em 1992 em limoeiros verdadeiros e laranjas doces nos municípios de Conchal e Engenho Coelho (Góes \& Feichtenberg, 1993). A doença se espalhou de forma endêmica por toda a região produtora de citros de Limeira, municípios de Araras, Rio Claro, Mogi Guaçu, Aguaí, Pirassununga, Santa Cruz das Palmeiras e Casa Branca (Feichtenberger, 1996; Góes, 1998).

A pinta preta dos citros é de grande importância econômica, pois causa depreciação estética dos frutos e acarreta prejuízos na comercialização dos frutos in natura no mercado externo em decorrência das barreiras fitossanitárias impostas pelos países como Estados Unidos e a Comunidade Européia. Quando ocorre alta infecção na região do pedúnculo de frutos em desenvolvimento pode haver queda prematura refletindo desta maneira na produção (Aguilar-Vildoso, 2002).

\subsubsection{Etiologia}

A pinta preta dos citros é uma doença de origem fúngica cuja fase sexual ou perfeita foi descrita em 1948 (Kiely, 1948), sendo denominada Guignardia citricarpa Kiely cuja forma assexual ou imperfeita corresponde a Phyllosticta citricarpa. A fase assexuada foi a primeira a ser descrita, em 1889 por McAlpine (McOnie, 1964), mas inicialmente denominada Phoma ciricarpa McAlpine (Roobs, 1990). Pseudotécios estão presentes somente na folhas de citros em decomposição no solo. São isolados ou agregados, globosos, imersos, de cor castanho-escuro a preta, com 95-125 $\mu \mathrm{m}$ de diâmetro, ostíolo não papilado, circular, com 10-17,5 $\mu \mathrm{m}$ de diâmetro e pseudoparáfises ausentes. Os ascos são cilíndricos-clavados (40-64 x 12-15 $\mu \mathrm{m})$, de parede bitunicada, contendo oito ascósporos unicelulares, hialinos, multigutulados, 
cilíndricos com o centro dilatado (12,5-1,6 x 4,5-6,5 $\mu \mathrm{m})$ e apêndices hialinos nas duas extremidades obtusas (Baldassari et al., 2001).

A fase assexual representada por $P$. citricarpa, produz picnídios em lesões nos ramos, frutos e folhas e em folhas em decomposição. Os picnídios são solitários, ás vezes agregados, globosos, com 115-190 $\mu \mathrm{m}$ de diâmetro, de coloração marrom escura para preta, ostíolo levemente papilado, circular e com 12-14,5 um de diâmetro. Os conídios possuem formato obovóide para elíptico, hialinos, unicelulares, multigutulados, com um apêndice hialino em uma das extremidades, base truncada e medem 8-10,5 x 5,5-7 $\mu \mathrm{m}$. O conidióforo é cilíndrico e alongado com $9 \mu \mathrm{m}$ de comprimento (Sutton \& Waterson, 1966; Baldassari et al., 2001).

Através de isolamentos realizados a partir de frutos ou folhas obtém-se colônias de coloração negra com bordos lobulados e aspecto granuloso. Devido ao desenvolvimento de picnídios em meio de cultivo, é comum o desenvolvimento simultâneo do estado espermácio, estado intermediário entre o anamórfico e o teleomófico. Neste estado, são produzidas espermácias baciliformes, que são células especializadas, masculinas, unicelulares que participam da reprodução sexual e que dará origem aos ascomas ou pseudotécios do estado teleomórfico (Alcoba et al., 2000).

\subsubsection{Sintomatologia e Epidemiologia}

Os órgãos atacados pela pinta preta dos citros podem ser em ordem de freqüência: frutos, folhas, pedúnculos, pecíolos, ramos verdes e espinhos. Uma das principais características desta doença é a ausência de sintomas típicos nos tecidos vegetais mesmo estando infectados (Aguilar-Vildoso, 2002). Nos frutos as lesões produzidas ficam restritas ao flavedo (epicarpo), desfavorecendo a comercialização de frutas in natura, no entanto, não alcançam o albedo (mesocarpo) do fruto (Góes, 1998). 
O surgimento de sintomas pode demorar até um ano (fase latente), dependendo da variedade e das condições ambientais. O aparecimento é favorecido pela luminosidade combinada com altas temperaturas, sendo comum encontrar frutos com maior número de lesões na face exposta à luz do sol. Há vários tipos de lesões, nomeadas de acordo com suas características, que podem variar dependendo do tamanho, fase de maturação do fruto, condições climáticas e tipo de esporo responsável pela infecção (Góes, 1998; Fundecitrus, 2000).

O sintoma mais típico e comum da doença é a mancha preta ou mancha dura, a qual geralmente surge quando os frutos iniciam a fase de mudança de cor da casca, levando a maturação externa. As lesões são deprimidas, de bordos bem definidos, tendo centro acinzentado e pontos escuros que constituem as frutificações (picnídios). Em frutos verdes, as lesões apresentam um circulo amarelo ao seu redor. Frutos colhidos e infectados, porém assintomáticos, podem apresentar os sintomas posteriormente, no entanto não exibindo áreas deprimidas e pontuações negras (Góes, 1998; Fundecitrus, 2000).

A mancha marrom ou sardenta ocorre em frutos maduros e em póscolheita. O sintoma é caracterizado por pequenas lesões de coloração pardoavermelhadas, levemente deprimidas, com bordos definidos e formato irregular, normalmente não apresenta as frutificações do patógeno.

A mancha virulenta é resultado da fusão dos diferentes tipos de sintomas. Caracteriza-se pela formação de lesões grandes que podem tomar grandes áreas do fruto no decorrer do desenvolvimento, são escuras ou de coloração marrom, com ou sem frutificações, de formato irregular podendo ser deprimidas ou não. Geralmente surge no final da safra quando os frutos estão maduros, e com ocorrência de altas temperaturas. A falsa melanose é semelhante a melanose dos citros causada pelo fungo Diaporthe citri. Ocorre em frutos em desenvolvimento, as lesões são pequenas, cerca de $2 \mathrm{~mm}$, circundadas por pontos pequenos e escuros com aproximadamente $1 \mathrm{~mm}$ de 
diâmetro. Ao contrário da melanose, as lesões não são ásperas. Em frutos ainda verdes ocorre o sintoma da mancha trincada, podendo atingir desde pequenas áreas até quase a totalidade do fruto. Quando o fruto amadurece, a lesão trinca e está sempre associada ao ácaro da falsa ferrugem (Phyllocoptruta oleivora). A mancha reticulada ocorre em frutos imaturos na forma de lesões superficiais de textura lisa e sem bordas definidas, possui coloração marrom escura a clara, aspecto encharcado e corpos de frutificação não estão presentes. Tais lesões podem tomar todo o fruto (Góes, 1998; Fundecitrus, 2000).

As folhas podem apresentar sintomas caracterizados por lesões de centro acinzentado, com bordos salientes marrom-escuros e circundados por um halo amarelo parecido com aquelas observadas nos frutos com sintomas de mancha dura. As lesões em folhas são freqüentemente observadas em tangerineira e limoeiros verdadeiros, e raramente em plantas de pomelo (Góes, 1998; Fundecitrus, 2000).

Segundo Kotzé (1988), os fatores que podem afetar de modo direto a epidemiologia da pinta preta dos citros são: disponibilidade de inóculo, clima favorável a infecção, ciclo de crescimento do hospedeiro e fase de maturação do fruto em relação a susceptibilidade a infecção e eventual desenvolvimento dos sintomas.

O ciclo primário da doença é constituído pela fase sexual de $G$. citricarpa, cujas estruturas infectivas são os ascósporos, responsáveis pela introdução do patógeno na área e o início da epidemia a cada ciclo da cultura, já o ciclo secundário é caracterizado pela fase assexual do fungo (Phyllosticta citricarpa), onde os conídios são responsáveis pelo aumento da doença na planta hospedeira e ao seu redor (Kiely, 1948; Aguilar-Vildoso, 2002).

As estruturas responsáveis pela formação de ascos e ascósporos, os pseudotécios, são encontrados maduros apenas em folhas caídas no solo e em fase intermediária de decomposição. A produção de ascósporos é influenciada pelas condições de temperatura e precipitação (Alcoba et al., 2000). Os 
ascósporos produzidos são lançados e carregados pelo vento e assim disseminados a grandes distâncias, podendo atingir até $25 \mathrm{Km}$ de distância (Klotz, 1973). A produção de esporos sexuais é de grande importância, pois além da capacidade de dispersão possuem maior viabilidade e tolerância ao ressecamento favorecendo a sobrevivência do patógeno no campo. Em São Paulo a queda das folhas ocorre o ano todo sendo mais intensa no inverno, o que favorece a disponibilidade de inóculo (Aguilar-Vildoso, 2002).

Os picnídios são estruturas produtoras de conídios, sendo importantes na disseminação de curta distância, cuja formação ocorre principalmente em lesões de frutos maduros, bem como em folhas velhas caídas e ocasionalmente presentes em folhas novas, hastes de frutos e ramos mortos (Smith, 1996). Os conídios emergem do picnídio através do ostíolo e estão cobertos por uma massa mucilaginosa. A mucilagem é rapidamente solubilizada e os conídios levados pela água das chuvas, irrigação ou orvalho podendo alcançar a superfície de um tecido susceptível e assim iniciar novas infecções As folhas infectadas quando caem no solo do pomar formam novos ascósporos, dando continuidade ao ciclo (Kiely, 1948; Kotzé, 1981; Robbs et al., 1985).

O período crítico para infecção ocorre após a queda das pétalas e estende-se por até seis meses de desenvolvimento dos frutos (Baldassari, 2001). Os esporos originados sexual ou assexuadamente germinam na superfície do órgão suscetível e emitem o tubo germinativo e apressório do qual se origina o "peg" de penetração que perfura e entra através da cutícula, originado uma pequena massa de micélio entre a cutícula e a epiderme do órgão afetado. Nesta fase o fungo pode permanecer dormente por até um ano. Este período de dormência ou infecção latente é interrompido quando o fruto atinge seu tamanho final e inicia a maturação, ou quando a folha já caída entra em processo de degradação. O fungo cresce a partir do micélio subcuticular e coloniza tecidos mais internos, produzindo os sintomas típicos da doença (McOnie, 1967; Kotzé, 1988). A manifestação da doença é influenciada de 
forma fundamental por fatores ambientais, como radiações solares intensas e altas temperaturas (Kotzé, 1981; Kotzé, 1996).

Diversos trabalhos apontam os conídios como sendo secundários como fonte de inóculo, pois não possuem mecanismo especial de liberação na atmosfera, ocorrendo em folhas em decomposição no solo, podendo alcançar frutos suscetíveis apenas por respingos de chuva. No entanto, a forma conidial é potencialmente importante como forma de inóculo quando em uma mesma planta frutos maduros infectados coabitam com frutos jovens de até seis meses de idade a contar da queda das pétalas (frutos susceptíveis). Nestas circunstâncias, os conídios formados nos frutos da estação anterior podem se disseminar para os frutos jovens (Kotzé, 1996).

\subsubsection{Controle}

Existem varias medidas a serem tomadas a fim de minimizar os prejuízos, tais como utilização de mudas sadias, boas condições de nutrição e sanidade, desinfestação de veículos, máquinas e equipamentos, retirada de restos vegetais e catação de frutas temporãs infectadas, controle de ervas daninhas, utilização de quebra ventos e irrigação nos períodos secos para evitar queda excessiva de folhas (Fundecitrus, 2000). Além desses cuidados, inclui-se a utilização de fungicidas protetores ou sistêmicos, isoladamente ou combinados, associados a óleo mineral ou vegetal, o que eleva o custo da produção. O emprego de fungicidas é o principal método de controle utilizado em pré e pós-colheita (Góes, 1998), no entanto, a utilização indiscriminada de fungicidas promoveu a seleção de isolados resistentes ao benomyl, o que levou a restrição ao seu uso (Ghini \& Kimati, 2000). 


\subsection{Controle biológico}

Desde o início da domesticação das plantas pelos humanos a 10.000 anos atrás, fitopatógenos têm causado perdas nos campos cultiváveis e têm reduzido o valor estético e o tempo de armazenamento (Punja \& Utkhede, 2003).

As plantas cultivadas podem ser consumidas frescas ou depois de processadas e podem ser produzidas em fazendas através de métodos de produção convencional ou orgânica ou ainda sob intenso manejo em condições ambientais controladas em casas de vegetação. No entanto, não são poupadas da destruição por fitopatógenos, os quais afetam raízes, caules, folhas, flores e frutos (Punja \& Utkhede, 2003).

O combate a doenças é altamente dependente de agrotóxicos, que são de modo geral, eficazes para controle de pragas, mas apresentam, por vezes, conseqüências indesejáveis. Os agrotóxicos são apontados como substancias altamente venenosas, que se acumulam no organismo e são capazes de causar câncer e mutações genéticas em descendentes (Lima et al., 2000).

O desafio para os produtores no controle de doenças tem aumentado cada vez mais com a demanda por produtos livres de resíduos químicos tóxicos e pela percepção do público em geral sobre o impacto potencial das práticas utilizadas no controle de doenças, como o uso de agrotóxicos, sobre a saúde dos seres humanos e sobre o meio ambiente. Tais pressões exercidas pela sociedade promoveram estabelecimento de políticas governamentais que restringem a utilização de agrotóxicos (Gullino \& Kuijpers, 1994; Ragsdale \& Sisler, 1994). Desta forma, agricultores, bem como os pesquisadores começaram a considerar o uso de métodos alternativos no combate a doenças (Punja \& Utkhede, 2003).

O controle alternativo no contexto da proteção de plantas contra fitopatógenos engloba o controle biológico e indução de resistência, e não inclui o controle químico clássico e o melhoramento genético de plantas para 
resistência a doenças. Alguns autores, no entanto, classificam a indução de resistência como um tipo de controle biológico (Pascholati, 1998). O controle biológico tem como premissa básica, manter a densidade populacional das espécies de pragas associadas à agricultura, em níveis economicamente e ecologicamente aceitáveis. (Lima et al., 2000). Em um conceito mais amplo, o controle biológico é definido segundo Baker \& Cook (1974) como "a redução da densidade de inóculo ou das atividades determinantes da doença, esta provocada por um patógeno ou parasita nos seus estados de atividade ou dormência, por um ou mais organismos, realizada naturalmente ou através da manipulação do ambiente, hospedeiro ou antagonista, ou pela introdução em massa de um ou mais antagonistas". Posteriormente, Cook \& Baker (1983) redefiniram o controle biológico como sendo "a redução da soma de inóculo ou das atividades determinantes da doença provocada por um patógeno, realizada por ou através de um ou mais organismos que não o homem".

No contexto particular deste estudo, o controle biológico de doenças de plantas pode ser definido simplesmente como "o controle de um microrganismo através de outros microrganismos".

Dentre os 200 produtos biológicos disponíveis no mercado, os biopesticidas, que possuem microrganismos como ingrediente ativo, representaram em 1995, apenas $0,7 \%$ do mercado mundial de pesticidas, mas que cresce entre 10 e $25 \%$ ao ano, ao passo que pesticidas químicos vêm crescendo a taxas entre 1 a $2 \%$. A grande fatia do mercado de biopesticidas (cerca de $80 \%$ ) é representada por produtos à base da bactéria Bacillus thuringiensis no controle de insetos. Outros exemplos de microrganismos comercializados são a Agrobacterium radiobacter no controle da galha da coroa causada por A. tumefaciens, o vírus Baculovirus anticarsia contra a lagarta desfolhadora (Anticarsia gemmmatalis) em soja, Colletotrichum gloeporioides f.sp. aeschynomene utilizado como bioherbicida em culturas de arroz e soja, Trichoderma harzianum no controle de Sclerotium rolfsii e a levedura Candida 
oleophila no controle de fitopatógenos em pós-colheita (Nardo \& Capalbo, 2000).

\subsubsection{Utilização de fungos e leveduras como agentes de biocontrole}

O entendimento do ciclo da doença e do ciclo de vida do patógeno são cruciais para o sucesso de qualquer estratégia de controle de uma determinada doença. A maioria dos fitopatógenos que afeta diversas culturas foi razoavelmente estudada e as informações sobre sua biologia estão disponíveis (Agrios, 1997).

A utilização de fungos e leveduras no controle de doenças requer uma interrupção de algum estágio da doença ou do ciclo de vida do patógeno, e isto pode ocorrer através de diversos mecanismos. A prevenção da infecção, redução na colonização do tecido hospedeiro, redução da esporulação ou da sobrevivência do patógeno podem proporcionar diferentes níveis de controle através da utilização de agentes biológicos (Punja \& Utkhede, 2003).

Muitos dos fungos e leveduras estão presentes naturalmente no interior ou próximos às folhas, raízes e outras estruturas como epífitas ou saprófitas, usando nutrientes disponíveis em vários nichos. Pesquisas no intuito de elucidar se estes microrganismos poderiam potencialmente ser utilizados como agentes de controle biológico tem se intensificado nos últimos 20 anos, e isto tem levado ao desenvolvimento e registro de diversos agentes microbianos de uso comercial empregados no controle de doenças. Logo em seguida a descoberta inicial, o desenvolvimento de agentes de controle biológico da fase laboratorial até a obtenção do produto comercial é uma tarefa muito difícil. É necessário obter diversas informações com relação à eficácia, modo de ação do agente em questão, bem como sobre a sobrevivência, colonização e potencial toxicidade para espécies não-alvo. Além disso, estudos com relação à formulação, estabilidade e vida de prateleira também são necessários (Lumsden, 1996; Mathre et al., 1999; Harman, 2000). 
Diversos fungos têm o seu sucesso comprovado como agentes de biocontrole e muitos outros estão sendo apontados como potenciais. Alguns exemplos a serem citados são: Trichoderma sp. no controle de Rhizoctonia solani, Sclerotium rolfsii, Fusarium spp e Pythium spp.; Gliocladium roseum tem sido observado parasitando fungos como Botrytis cinerea, Phomopsis sclerotioides e Helminthosporium sativum; Coniothyrium minitans, um hiperparasita de fungos formadores de escleródios como Sclerotinia sclerotiorum e Botrytis fabae; Talaromyces flavus produz diversos metabólicos capazes de impedir o desenvolvimento de Verticillium dahliae; Ampelomyces quisqualis no controle de Sphaerotheca fuliginea (Melo, 1998).

O controle biológico de patógenos de ocorrência na pós-colheita pode ser feito durante o ciclo da cultura ou após a colheita. O controle, ainda no campo, tem como objetivo evitar a penetração dos patógenos nos tecidos de frutos e hortaliças e seu posterior desenvolvimento durante o armazenamento. O controle após a colheita tem dois objetivos: evitar que os patógenos latentes nos tecidos causem podridões e impedir novas infecções (Bettiol \& Ghini, 1995).

Wisniewski et al. (1991) comentaram que a leveduras têm se mostrado promissoras no controle da doenças que ocorrem em pós-colheita, devido a facilidade de integrar o seu uso ao ambiente e sistema usado para manejo da fruta. As primeiras espécies citadas, pela eficiência no controle de doenças em pós-colheita de frutas e hortaliças, foram Acremonium breve, Candida guillermondii, C. albidus var. aerius, Debaryomyces hansenii, Hanseniaspora uvarum e Cryptococcus laurentii, sendo que as leveduras $D$. hansenii, Rhodotorula mucilaginosa e $C$. oleophila são as mais citadas na pós-colheita de citros (Valdebenito-Sanhueza, 2000).

As leveduras têm sido os organismos preferencialmente utilizados quando o objetivo é a proteção de frutos destinados ao consumo in natura. Tal escolha é justificada pelo fato destes organismos não serem bons produtores de antibióticos, substâncias químicas estas, cuja presença é indesejável em 
frutos a serem consumidos pelo homem (Valdebenito-Sanhueza, 2000). Biofungicidas preparados com leveduras para uso em pós-colheita estão em desenvolvimento em vários países. Entre esses produtos encontra-se disponível para uso comercial o produto "Aspire", constituído de Candida oleophila, registrado em Israel e EUA para utilização no controle de doenças de pós-colheita causadas por Botrytis e Penicillium (Valdebenito-Sanhueza, 2000).

A vantagem no uso de leveduras no biocontrole foliar e doenças de pós-colheita é pelo fato destes organismos serem os maiores componentes da comunidade microbiana na superfície de folhas, frutos e vegetais (Wilson \& Wisniewski, 1989). Elas são agentes de controle potencialmente mais efetivos, pois são fenotipicamente mais adaptadas a estes nichos e são hábeis na colonização e competição por nutrientes e espaço em frutos e superfícies foliares (McLaughlin et al. 1990; Filonow, 1998).

A busca por agentes de controle biológico tem dado oportunidade para que fitopatologistas, micologistas, geneticistas, bioquímicos e biologistas moleculares interajam de forma a melhor compreender como estes microrganismos reduzem o desenvolvimento do patógeno e da doença. Não há uma característica única que possa ser identificada nos agentes de controle biológico para explicar como eles se manifestam como antagonistas aos fitopatógenos, entretanto, diversas características importantes têm surgido a partir das investigações científicas com relação aos modos de ação (Punja \& Utkhede, 2003).

Os mecanismos pelos quais fungos e leveduras podem reduzir 0 crescimento e desenvolvimento de fitopatógenos fúngicos, e reduzir a doença são: parasitismo, produção de compostos antibióticos, produção de enzimas extracelulares, interferência nos fatores de patogenicidade, indução de resistência na planta hospedeira, e competição por nutrientes e nichos de colonização. É provável que os diferentes mecanismos atuem em sinergia durante a interação antagônica (Punja \& Utkhede, 2003). 


\subsubsection{Micoparasitismo}

Os primeiros relatos que demonstraram que patógenos fúngicos podem ser parasitados por outros fungos foram feitos na década de 30. A maioria dos estudos é referente a diversas espécies de Trichoderma (Howell, 2003). No final da década de 80 , foram identificadas leveduras capazes de reduzir o crescimento e a produção de esporos de fitopatógenos fúngicos (Avis \& Bélanger, 2001; Urquhart \& Punja, 2002). Também é utilizado o termo hiperparasitismo, o qual refere-se a um microrganismo que ataca outro sendo este último parasita de uma planta.

Neste tipo de interação é necessário que fitopatógenos e micoparasitas estejam fisicamente próximos. A maioria das observações tem sido feitas em placas de Petri ou em tecido vegetal destacado, mantido sob condições controladas. Ampelomyces quisqualis mostrou-se parasita sobre hifas e conídios de oídio (Rotem et al., 1999), enquanto Contiothyrium minitans é micoparasita sobre escleródios de Sclerotinia spp. (Budge \& Whipps, 2001; Giczey et al., 2001), e Pythium oligandrum parasita outras espécies de Pythium e outros fungos (Benhamou et al., 1997; Madsen \& Neergaard, 1999).

O parasitismo e a degradação de hifas do fungo patogênico por leveduras antagonistas tem sido demonstrados. Esses efeitos têm sido vinculados à aderência das células da levedura ás hifas dos fungos e a elevada produção de glucanase, a partir de diferentes fontes de carbono (ValdebenitoSanhueza, 2000). A levedura Pichia guilliermondii inibe Botrytis cinerea, e adere fortemente ao micélio fúngico (Wisniewski et al., 1991).

Estes resultados têm agora sido estendidos dos laboratórios para as condições de casa de vegetação e campo, e mostram redução significativa de doenças. 


\subsubsection{Produção de antibióticos}

A produção de compostos antibióticos é característica de muitos fungos utilizados como agentes de biocontrole. Espécies de Trichoderma e Gliocladium, bem como a levedura Pseudozyma, são conhecidos produtores de diversos metabólitos secundários com amplo espectro de atividade antimicrobiana, e já são produtos comerciais (Punja \& Utkhede, 2003). Os antibióticos produzidos pela levedura Pseudozyma floculosa são uma mistura de derivados de ácidos graxos que afetam a permeabilidade de membrana do organismo alvo, inibindo assim o seu crescimento (Avis \& Bélanger, 2001). A obtenção de mutantes incapazes de produzir antibióticos e avaliação da sua eficiência pode fornecer evidências conclusivas sobre o papel dos antibióticos na supressão de doenças. Um mutante de Trichoderma virens, incapaz de sintetizar gliotoxina e gliovirina perdeu a sua habilidade de controlar fungos que infectam raízes como Pythium, no entanto, trabalhos utilizando mutantes com deficiência na produção de gliotoxina ainda permaneceram capazes de inibir Rhizoctonia. Desta forma, pode-se supor que outros atributos em Trichoderma tenham papel importante no controle de fitopatógenos (Howell, 2003). Cheng et al. (2003) usando mutagênese de inserção que tornava Pseudozyma defectiva na produção do glicolipídio floculosina teve significante redução na atividade de biocontrole contra oídio.

De modo geral, as leveduras não são produtoras de antibióticos (Droby et al., 1991). Mc Cormack et al. (1994) concluíram que alguns isolados das leveduras Aureobasidium pullulans e Sporobolomyces, somente quando mantidos em condições de exaustão de nutrientes e, portanto, de aumento de demanda de competividade, apresentavam produção importante desse tipo de metabólito. 


\subsubsection{Produção de enzimas extracelulares}

As células fúngicas são envoltas por paredes celulares rígidas que mantém a forma e protege a célula de intempéries e hostilidade ambientais, proporciona ambiente adequado à organização e ocorrência de processos vitais, atua como filtro para determinadas moléculas e serve como receptor para hormônios e toxinas. Em resumo, ela serve como barreira às ações exercidas pelos microrganismos antagonistas. Poderá ter sucesso o antagonista que tiver êxito em romper a parede celular do patógeno ou interromper os processos relacionados a sua síntese (Lorito et al., 1996; Lima et al., 2000). A parede celular é composta por carboidratos, quase todos sob a forma de polissacarídios (80 a 90\%), tais como quitina, $\beta-1,3$ e $\beta$-1-6-glucanas, além de proteínas e lipídios em quantidades significativas. A produção de enzimas hidrolíticas capazes de hidrolisar os componentes da parede celular podem desempenhar um importante papel no processo antagônico (Lima et al., 2000).

A secreção de enzimas hidrolíticas, particularmente quitinases e glucanases, é uma característica comum em muitos agentes de biocontrole. Quando o gene ech42, responsável pela codificação de uma quitinase, é interrompido em Trichoderma virens e $T$. harzianum spp., é evidenciada uma perda na capacidade de controle dos patógenos Rhizoctonia solani e Botrytis cinerea, respectivamente quando comparado as linhagens selvagens (Baek et al., 1999; Woo et al., 1999). No entanto, a superexpressão de diversos genes em Trichoderma codificantes de enzimas como quitinases (ech42, chit33) (Baek et al., 1999; Limón et al., 1999), endoglucanase (eg11) (Migheli, et al., 1998) e proteinase (prb1) (Flores et al., 1997) melhorou substancialmente o potencial antagonista dos agentes contra fitopatógenos como Rhizoctonia e Pythium, tanto in vitro como in vivo.

A produção microbiana de enzimas é de importância comercial e as leveduras são o grupo de organismos mais citado nos estudos de aproveitamento industrial desses metabólitos e o potencial de produção 
enzimática está mais fortemente relacionada à característica do isolado do que ao grupo de leveduras (Machado \& Linardi, 1990).

A importância da produção e excreção de enzimas hidrolíticas na capacidade de biocontrole em leveduras depende do organismo em questão, sendo que Candida guilliermondii e C. oleophila foram capazes de expressar altos níveis de $\beta$-1,3-exoglucanase e quitinase no controle de $B$. cinerea em tomate (Saligkarias et al., 2002). A localização in situ de várias enzimas líticas durante as interações entre o agente de controle e patógeno permanece obscuro, no entanto já foram evidenciados através de microscopia, a desintegração e o colapso de hifas dentre outras estruturas fúngicas, fenômeno este que pode ser atribuído à atividade enzimática (Benhamou \& Chet, 1997; Carsolio et al., 1999; Rotem et al., 1999; Zeilinger et al., 1999). Foi demonstrado que Pichia anomala produz endo- $\beta-1,3-$ glucanase e induz lise da ponta das hifas entre outras deformações em B. cinerea (Jijakli \& Lepoivre, 1998). A fixação de leveduras à hifa do fitopatógeno fúngico é um importante fator para a atividade de controle, potencializando o efeito das enzimas degradadoras de parede celular (Cook et al., 1997). Com base nas informações obtidas através de pesquisas relacionadas à produção de enzimas extracelulares por fungos e leveduras utilizadas como agentes de controle biológico, foi possível demonstrar de forma concreta o papel deste fator na redução do desenvolvimento e infecção de fitopatógenos. Também é previsível que haja uma sinergia entre enzimas e antibióticos. Enzimas hidrolíticas na presença de antibióticos suprimem de forma significativa o crescimento de $B$. cinerea e Fusarium oxysporum comparado com qualquer um dos dois sozinhos (Schirmbock et al., 1994; Lorito et al., 1996). 


\subsubsection{Ação sobre fatores de patogenicidade}

Diversos fatores de patogenicidade podem influenciar na capacidade de fitopatógenos em invadir o tecido hospedeiro. A interrupção de um destes fatores pode tornar o patógeno incapaz de infectar. A produção de cisteína proteases por Trichoderma harzianum foi capaz de inibir a atividade de enzimas hidrolíticas, em especial poligalacturonases, um importante fator de patogenicidade em muitos fungos. Desta forma $T$. harzianum foi capaz de afetar o desenvolvimento do mofo cinzento causado por B. cinerea. (Kapat et al., 1998; Elad \& Kapat, 1999). A produção de proteases inativou a enzima do patógeno através da clivagem da molécula. A redução da doença também foi demonstrada utilizando os extratos contendo as proteases do filtrado de cultura de Trichoderma, sendo este efeito ausente quando adicionado inibidor de proteases (Kapat et al., 1998).

\subsubsection{Competição por nutrientes e nichos de colonização}

Fitopatógenos fúngicos necessitam de sítios de entrada para terem acesso ao interior do tecido do hospedeiro. Em parasitas obrigatórios, isto é usualmente obtido através da penetração direta da hifa através da cutícula e epiderme da planta, já no caso dos parasitas facultativos que são mais saprofíticos, a entrada é feita através de lesões, tecidos em senescência, ou aberturas naturais como estômatos e lenticelas. Tais locais são de modo geral ricos em nutrientes devido ao exudação de açúcares e aminoácidos. Microrganismos de controle que tem capacidade de competir de forma efetiva por estes sítios de infecção e usar os nutrientes disponíveis podem deslocar de forma eficaz o patógeno por impedir a germinação de propágulos ou a infecção (Punja \& Utkhrde, 2003).

Espécies de Trichoderma e Gliocladium podem se sobressair em relação ao fitopatógeno, principalmente se aplicados antes da chegada do 
patógeno (Harman, 2000). Isolados não patogênicos de $F$. oxysporum competem por fontes de nutrientes e sítios de colonização em raízes (Eparvier \& Alabouvette, 1994).

Competição por nutrientes tem sido sugerida como o principal modo de ação de diversas leveduras, tais como $P$. guilliermondii contra Penicillium digitatum (Droby et al., 1989), Candida guilliermondii, Cryptococcus laurentii e Metschnikowia pulcherima contra B. cinerea e Penicillium expansum (Roberts, 1990; Elad et al., 1994; Piano et al., 1997; Saligkarias et al., 2002; Vero et al., 2002). Leveduras que controlam fitopatógenos podem utilizar-se deste mecanismo para colonizar tecidos em senescência e injuriados prevenindo a infecção de fitopatógenos (Filonow, 1998).

Droby et al. (1989) demonstraram que através da adição de nutrientes exógenos, houve redução na eficácia de controle de $P$. guilliermondii contra $P$. digitatum. Na maioria dos casos a competição por nutrientes é um fator provável e lógico, contudo, é de difícil comprovação por ser difícil a exclusão de outros mecanismos.

\subsubsection{Indução de resistência no hospedeiro}

Plantas superiores são capazes de se defender contra patógenos em potencial prevenindo e restringindo a penetração, crescimento e multiplicação através da indução de diversos componentes físicos e bioquímicos. A indução é desencadeada por moléculas eliciadoras ou agentes indutores (Benhamou, 1996). A indução de resposta do hospedeiro por fungos e leveduras utilizadas como agentes de biocontrole pode ser desencadeada pela colonização do tecido hospedeiro, produção de moléculas eliciadoras e compostos sinalizadores, e produção de substâncias promotoras de crescimento. Candida oleophila foi capaz de induzir resistência em videiras contra Penicillium digitatum. 
Droby et al. (1991) demonstraram que Pichia guilliermondii pode estimular a produção de etileno em videira, enquanto Rodov et al. (1994) evidenciaram que esta levedura induzia a produção de fitoalexinas em citros. Aureobasidium pullulans e Candida saitoana induziram o acúmulo de $\beta$-1,3glucanases, quitinases e peroxidases em maçãs (Ippolito et al., 2000; El Ghaouth et al., 2003).

Martins et al. (1986) e Martins (1991) evidenciaram que a aplicação de filtrados obtidos de extratos de Saccharomyces cerevisiae sobre folhas destacadas de cafeeiro, 72 horas antes da inoculação do fungo Hemileia vastatrix, agente causal da ferrugem alaranjada, induzia resistência ao patógeno sem afetar a germinação dos urediniósporos e a formação de apressório. Outros inúmeros relatos descrevem a capacidade de $\mathrm{S}$. cerevisiae em ativar mecanismos de defesa em plantas contra patógenos. Suspensões de células de levedura, bem como o filtrado dessas suspensões foram capazes de induzir resistência em plantas de sorgo contra Colletotrichum graminicola e Exserohilum turcicum (Lopez, 1991; Piccinin, 1995), milho contra C. graminicola e E. turcicum (Silva \& Pascholati, 1992; Stangarlin \& Pascholati, 1994) e eucalipto contra Botrytis cinerea (Piccinin, 1995).

\subsubsection{Saccharomyces cerevisiae e controle biológico}

S. cerevisiae é um fungo ascomiceto unicelular com tamanho médio de $5 \mu \mathrm{m}$. Pode originar ascos sem a produção de ascocarpos, sendo incluída na ordem Saccharomycetales. O habitat natural dessa levedura é a superfície de frutas. No entanto a mesma se tornou, uma das mais importantes ferramentas da biotecnologia, sendo comumente envolvida na produção de etanol, bebidas alcoólicas e panificação. Em muitos destes processos a sua função é apenas como um agente biológico de transformação, uma vez que ao término do processo produtivo é descartada, sendo considerada como subproduto. Tal fato é notório na produção de etanol. No Brasil, o volume de células geradas 
durante o processo fermentativo para produção de etanol é extremamente significativo, chegando a 300 mil toneladas ao ano (Baptista, 2001). Desta maneira, vislumbra-se uma necessidade real de se buscar novas aplicações deste organismo após a sua utilização em processos primários.

O isolado S20 de S. cerevisiae, utilizada na indústria alimentícia, foi eficiente no controle de doenças em pós-colheita, reduzindo $100 \%$ da podridão em limões causada por Penicillium digitatum (Cheah et al., 1995b) e proporcionando $51 \%$ de redução na podridão em abobrinha causada por Fusarium sambucium (Cheah et al., 1995a). Em frutos de kiwi a incidência da podridão causada por Botrytis cinerea foi reduzida em 61\% (Cheah et al., 1994). Segundo os autores, a levedura teria atuado controlando os patógenos através de competição por espaço e nutrientes e não foi detectada a produção de antibióticos.

Suspensões de S. cerevisiae e os filtrados dessas suspensões, obtidas a partir do fermento biológico fresco para panificação, promoveram redução in vitro da germinação e do crescimento micelial de Colletotrichum graminicola isolado de sorgo (Lopez, 1991) e milho (Silva et al., 1988) e da germinação de Exserohilum turcicum, isolado de milho (Stangarlin \& Pascholati, 1994). 


\section{MATERIAL E MÉTODOS}

\subsection{Material biológico}

\subsubsection{Fungo fitopatogênico}

O fungo Phyllosticta citricarpa (McAlpine) Petrak (teleomorfo: Guignardia citricarpa Kiely) foi isolado a partir de lesões em frutos de laranja. Para tal, fragmentos de tecido da região de transição entre a área lesionada e a área sadia foram retirados, imersos em álcool $70 \%(\mathrm{v} / \mathrm{v})$ por 30 a $60 \mathrm{~s}$. Em seguida, os fragmentos foram transferidos para solução de hipoclorito de sódio $2 \%(\mathrm{v} / \mathrm{v})$ por 2 a $3 \mathrm{~min}$. Após a desinfestação, os fragmentos foram lavados com água destilada esterilizada e transferidos sob condições assépticas para meio ágar-água. Após a formação de micélio ( 3 dias) este foi transferido e mantido em meio batata-dextrose-ágar (BDA).

\subsubsection{Levedura antagonista}

Foram testadas seis linhagens de Saccharomyces cerevisiae isoladas em processos de fermentação alcoólica: BG-1, CR-1, CAT-1, KD-1, K-1 e PE-2. Essas linhagens foram cedidas pelo Prof. Dr. Luiz Carlos Basso da área de Bioquímica e Fermentação Alcoólica do Departamento de Ciências Biológicas da Esalq/USP. 


\subsection{Meios de cultura e condições de cultivo}

O fungo G. citricarpa foi repicado para placas de Petri contendo meio BDA e mantidas $26^{\circ} \mathrm{C}$, sob fotoperíodo de $12 \mathrm{~h}$ (lâmpada fluorescente).

Meio BDA

Batata $200 \mathrm{~g}$

Dextrose $20 \mathrm{~g}$

Ágar $15 \mathrm{~g}$

Água destilada $1000 \mathrm{~mL}$

As linhagens de levedura foram cultivadas em meio "Yeast Extract Peptone Dextrose" (YEPD) a $32^{\circ} \mathrm{C}$, sob luz ambiente a $90 \mathrm{rpm}$.

Meio YEPD

Extrato de levedura

$10 \mathrm{~g}$

Peptona

$10 \mathrm{~g}$

Dextrose

$20 \mathrm{~g}$

Água destilada

$1000 \mathrm{~mL}$

\subsection{Seleção de linhagens de S. cerevisiae antagônicas a G. citricarpa}

Com uma alça de semeadura contendo a suspensão de levedura, foi realizada uma estria em placa de Petri de $90 \mathrm{~mm}$ de diâmetro contendo meio BDA a $20 \mathrm{~mm}$ da borda. Um disco de micélio $(6 \mathrm{~mm})$ do fitopatógeno foi posicionado a $32 \mathrm{~mm}$ da borda e a $32 \mathrm{~mm}$ da estria do antagonista. O controle consistia na placa contendo o patógeno na ausência da levedura. As placas foram mantidas a $26{ }^{\circ} \mathrm{C}$ sob fotoperíodo de $12 \mathrm{~h}$. O crescimento radial do micélio foi avaliado através da média entre duas medições diametralmente opostas, quando o bordo das placas controle foi atingido pela colônia. Foram utilizadas cinco repetições por linhagem de levedura avaliada. 


\subsection{Produção de compostos voláteis}

Para verificar a produção de metabólitos voláteis pelas linhagens da levedura, foi realizado um ensaio em que foram utilizadas placas de poliestireno divididas ao meio, contendo meio BDA. Em um dos lados foi feita uma estria com a levedura antagônica, ou $30 \mu \mathrm{L}$ da suspensão foi espalhada sobre o meio. No lado oposto da placa, foi adicionado um disco de micélio $(5 \mathrm{~mm})$ do fitopatógeno. $\mathrm{Na}$ placa controle foi feito estriamento com meio YEPD ou adicionado $30 \mu \mathrm{L}$ do mesmo meio. As placas foram mantidas a $26{ }^{\circ} \mathrm{C}$ sob fotoperíodo de $12 \mathrm{~h}$. A avaliação do crescimento radial do micélio foi feita através da média entre duas medições diametralmente opostas, quando a colônia das placas controle atingiu os bordos. Ao término do experimento, os discos de ágar contendo micélio que tiveram o crescimento inibido, foram transferidos para novas placas contendo meio BDA na ausência da levedura antagonista, objetivando determinar a natureza fungistática ou fungitóxica do volátil liberado pela levedura.

\subsection{Obtenção do filtrado de cultura, filtrado de cultura autoclavado e da levedura autoclavada}

A linhagem de levedura CR-1 foi transferida através de uma alça de inoculação para $2,5 \mathrm{~mL}$ de meio YEPD e mantida a $32^{\circ} \mathrm{C}$ por $12 \mathrm{~h}$. Decorrido este período, a suspensão de leveduras foi transferida para erlenmeyer de 250 $\mathrm{mL}$ contendo $100 \mathrm{~mL}$ do meio YEPD pré-aquecido a $32{ }^{\circ} \mathrm{C}$. O cultivo foi realizado a $32{ }^{\circ} \mathrm{C}$, sob agitação de $90 \mathrm{rpm}$, por $24 \mathrm{~h}$. Após este período, foi realizada centrifugação a $5000 \mathrm{~g}$ durante $10 \mathrm{~min}$ a $5{ }^{\circ} \mathrm{C}$. O sobrenadante foi retirado e esterilizado através de filtração em membrana de nitrocelulose com diâmetro de poro de 0,2 $\mu \mathrm{m}$ (filtrado de cultura). Uma parte deste filtrado foi ainda submetida à autoclavagem a $121^{\circ} \mathrm{C}$ por $20 \mathrm{~min}$ (filtrado de cultura autoclavado). O sedimento constituído pelas células de levedura foi 
ressuspenso em $100 \mathrm{~mL}$ de água destilada esterilizada e centrifugado novamente, sendo este processo de lavagem repetido mais três vezes a fim de se retirar o meio de cultura ainda presente. A suspensão celular teve a concentração ajustada para $1 \times 10^{8}$ células $/ \mathrm{mL}$, através de contagem em câmara de Neubauer, e posteriormente procedeu-se a inativação celular através de autoclavagem (levedura autoclavada).

\subsection{Efeito do filtrado de cultura, filtrado de cultura autoclavado e da levedura autoclavada sobre o crescimento micelial de G. citricarpa}

Alíquotas de $500 \mu \mathrm{L}$ dos tratamentos constituídos pelo filtrado de cultura, filtrado de cultura autoclavado, levedura autoclavada e meio YEPD foram adicionados superficialmente sobre placas de Petri de $90 \mathrm{~mm}$ de diâmetro, contendo meio BDA, e espalhadas com auxílio de uma alça de Drigalsky. Aguardou-se $12 \mathrm{~h}$ para que o meio absorvesse os tratamentos e um disco de micélio de $6 \mathrm{~mm}$ de diâmetro foi colocado no centro das placas. $O$ controle foi composto por placas que receberam $500 \mu \mathrm{L}$ de água esterilizada. As placas foram mantidas a $26^{\circ} \mathrm{C}$ sob fotoperíodo de $12 \mathrm{~h}$. A avaliação do crescimento radial do micélio foi feita através da média entre duas medidas diametralmente opostas até que a colônia de algum dos tratamentos atingisse o bordo. Foram utilizadas cinco repetições para cada tratamento.

\subsection{Produção de enzimas hidrolíticas}

Para verificar a produção e liberação de enzimas hidrolíticas, a linhagem de levedura CR-1 foi transferida através de uma alça de inoculação para $2,5 \mathrm{~mL}$ de meio YEPD e mantida a $32{ }^{\circ} \mathrm{C}$ por $12 \mathrm{~h}$. Decorrido este período, $1 \mathrm{~mL}$ da suspensão de leveduras foi transferido para erlenmeyer de $125 \mathrm{~mL}$ contendo $50 \mathrm{~mL}$ de meio YEPD e YEPD modificado, ou seja, com preparação de parede celular de $G$. citricarpa a $1 \%(\mathrm{~m} / \mathrm{v})$ (conforme descrito a seguir em 
3.7.1) em substituição à glicose. $\mathrm{O}$ cultivo foi realizado a $32^{\circ} \mathrm{C}$, sob agitação a 90 rpm. Foram utilizados 2 frascos para cada meio. Nos períodos de 12, 24, 36 , 48 e $60 \mathrm{~h}$, uma alíquota de $2 \mathrm{~mL}$ foi retirada e centrifugada a $10000 \mathrm{~g}$ durante $10 \mathrm{~min}$ a $5{ }^{\circ} \mathrm{C}$. O sobrenadante foi utilizado para avaliação das atividades de quitinase, $\beta$-1,3-glucanase e protease.

\subsubsection{Obtenção da preparação de parede celular (PPC)}

Para a preparação da parede celular (PPC) 4 discos de micélio de $G$. citricarpa foram adicionados a erlenmeyers $(250 \mathrm{~mL})$ contendo $100 \mathrm{~mL}$ de meio batata-dextrose (BD). O cultivo foi realizado em condições de temperatura e luz ambiente durante 10 dias sob agitação (150 rpm). O micélio foi coletado através de filtração a vácuo, lavado diversas vezes com água destilada. O material foi homogenizado em $100 \mathrm{~mL}$ água destilada por 5 min e centrifugado por $10 \mathrm{~min}$ a $5000 \mathrm{~g}$. O sobrenadante foi descartado e o excesso de água retirado. Em seguida, procedeu-se a maceração do tecido micelial em almofariz na presença de nitrogênio líquido e, posteriormente, foram adicionados $100 \mathrm{~mL}$ de água destilada. O material foi submetido a 3 ciclos de centrifugação e ressuspensão. Em seguida, o sedimento foi submetido à secagem a $55^{\circ} \mathrm{C}$ por $12 \mathrm{~h}$ e se constituiu na preparação de parede celular do fungo (Saligkarias et al., 2002).

\subsection{Atividades enzimáticas}

\subsubsection{Determinação de açúcares redutores}

A determinação de açúcares redutores liberados durante os ensaios enzimáticos (quitinase e $\beta$-1,3-glucanase) foi realizada segundo método descrito por MILLER (1959), utilizando o reagente de ácido 3,5-dinitrosalicílico (ADNS). Para isto, $250 \mu \mathrm{L}$ da mistura de reação foram adicionados a $250 \mu \mathrm{L}$ do reagente ADNS e a solução foi aquecida em banho de água fervente por $5 \mathrm{~min}$. Após o resfriamento em gelo até a temperatura de $25{ }^{\circ} \mathrm{C}$, a solução foi diluída 
com $2,5 \mathrm{~mL}$ de água destilada, homogeneizada e foi determinada a absorbância a $540 \mathrm{~nm}$, contra branco apropriado.

\subsubsection{Quitinase}

A produção de quitinase foi avaliada através da liberação de NAG (Nacetil glucosamina), a partir do substrato glicol quitina. Para tanto, $100 \mu \mathrm{L}$ do meio de cultivo da levedura foi misturado com $200 \mu \mathrm{L}$ de tampão Mcllvaine, $\mathrm{pH}$ 6,0 , e $100 \mu \mathrm{L}$ de glicol quitina $0,01 \%(\mathrm{~m} / \mathrm{v})$ neste mesmo tampão. Após incubação por 15 min a $37^{\circ} \mathrm{C}$, a reação foi interrompida através da adição de $250 \mu \mathrm{L}$ do reagente ADNS a $250 \mu \mathrm{L}$ da mistura de reação, determinando-se o teor de açúcares redutores liberados como anteriormente citado (item 3.8.1). A cubeta de referência (branco) consistiu na mistura de reação na presença do tampão em substituição ao meio de cultivo. $O$ valor da leitura foi subtraído do obtido pelo controle negativo que apresentou o tampão em substituição ao substrato (glicol quitina). A atividade enzimática foi expressa em $\mathrm{U} / \mathrm{mL}$, onde uma unidade de atividade $(U)$ foi definida como $1 \mu \mathrm{g}$ de açúcar redutor liberado ( $\mathrm{N}$-acetil glucosamina) enzimaticamente da glicol quitina por minuto nas condições de ensaio.

\subsection{3 $\beta-1,3-$ glucanase}

A atividade de glucanase foi determinada pela quantificação colorimétrica de glicose liberada do substrato laminarina, através da dosagem de açúcares redutores (item 3.8.1). A mistura da reação, incubada a $37^{\circ} \mathrm{C}$ por 1 h, continha $50 \mu \mathrm{L}$ de tampão acetato sódio $0,1 \mathrm{M}, \mathrm{pH} 5,0,200 \mu \mathrm{L}$ do meio de cultivo e $250 \mu \mathrm{L}$ de laminarina $(4,0 \mathrm{mg} / \mathrm{mL}$ ) (Abeles \& Foence, 1970). Após esse período, a reação foi paralisada através da adição de $250 \mu \mathrm{L}$ do reagente ADNS a $250 \mu \mathrm{L}$ da mistura de reação, determinando-se o teor de açúcares 
redutores liberados. A leitura de absorbância a $540 \mathrm{~nm}$ foi feita contra a mistura de reação contendo tampão em substituição ao meio de cultivo, sendo subtraído de cada amostra o valor do controle negativo que consistia na mistura reação na presença de tampão substituindo o substrato. As leituras de absorbância foram plotadas em curva padrão para glicose e a atividade enzimática expressa em $\mathrm{U} / \mathrm{mL}$, onde uma unidade de atividade $(U)$ foi definida como $1 \mu \mathrm{g}$ de açúcar redutor liberado (medido como glicose) da laminarina por minuto nas condições de ensaio. A atividade também foi expressa como atividade específica $\mathrm{U} / \mathrm{mg}$ de proteína. A quantificação de proteínas totais foi efetuada pelo método de Bradford (1976), utilizando albumina de soro bovino como padrão.

\subsubsection{Proteases}

Para avaliação da atividade proteolítica, $0,5 \mathrm{~g}$ de caseína foi dissolvida em $40 \mathrm{~mL}$ de água destilada e deixada sob agitação durante $20 \mathrm{~min}$. Em seguida, foi adicionado $1 \mathrm{~mL}$ de $\mathrm{NaOH} 1 \mathrm{M}$ e 2,5 mL de Tris $1 \mathrm{M}$. Após um período de agitação, com a dissolução da caseína, o pH foi ajustado para 7,8 com ácido fosfórico $85 \%$. O volume final foi completado para $100 \mathrm{~mL}$ obtendose assim a solução final de substrato $0,5 \%(\mathrm{~m} / \mathrm{v})$.

Para a reação, $500 \mu \mathrm{L}$ do substrato foi incubado com $200 \mu \mathrm{L}$ da amostra a $30{ }^{\circ} \mathrm{C}$ durante $30 \mathrm{~min}$. A reação foi interrompida através da adição de $650 \mu \mathrm{L}$ de ácido tricloroacético (TCA) $10 \%(\mathrm{~m} / \mathrm{v})$, seguida de centrifugação a $10000 \mathrm{~g}$ por $15 \mathrm{~min}$. A atividade foi determinada através da leitura de absorbância a $280 \mathrm{~nm}$ do sobrenadante contra branco preparado através da adição de TCA previamente ao acréscimo da amostra. Uma unidade de atividade enzimática foi definida como a quantidade de enzima que catalisa o aumento de 1,0 unidade na absorbância a $280 \mathrm{~nm}$ sob as condições de ensaio. 


\section{RESULTADOS}

\subsection{Seleção de linhagens de S. cerevisiae antagônicas a G. citricarpa}

Neste experimento, objetivou-se selecionar dentre seis linhagens de $S$. cerevisiae (BG-1, CR-1, CAT-1, KD-1, K-1 e PE-2), a que exibia maior atividade antifúngica in vitro em relação ao fitopatógeno G. citricarpa. A linhagem CR-1 apresentou maior capacidade antagônica significativa, inibindo o crescimento micelial em cerca de 73\%, seguida pelas linhagens K-1 (61\%) e CAT-1 (59\%). As linhagens KD-1 e PE-2 apresentaram menor efeito $(31,5$ e $34 \%$, respectivamente), já BG-1 não inibiu significativamente em relação ao controle (11\%) (Figura 1 e 2).

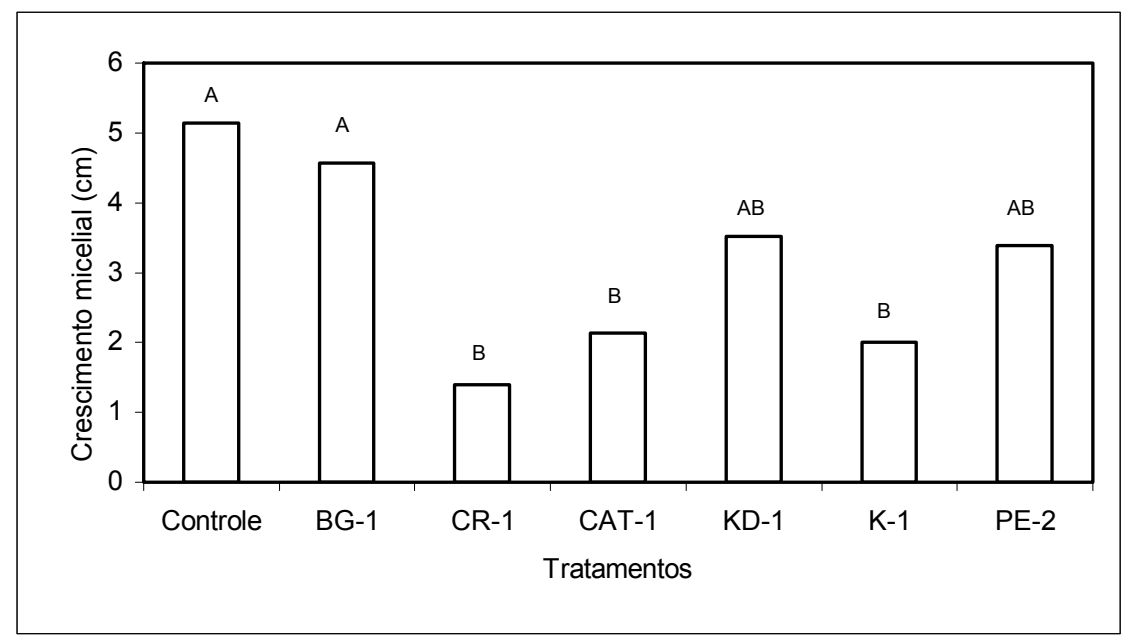

Figura 1 - Efeito antagônico in vitro de diferentes linhagens de S. cerevisiae frente a G. citricarpa. Médias seguidas pelas mesmas letras não diferem entre si pelo teste de Tukey a $1 \%$ 


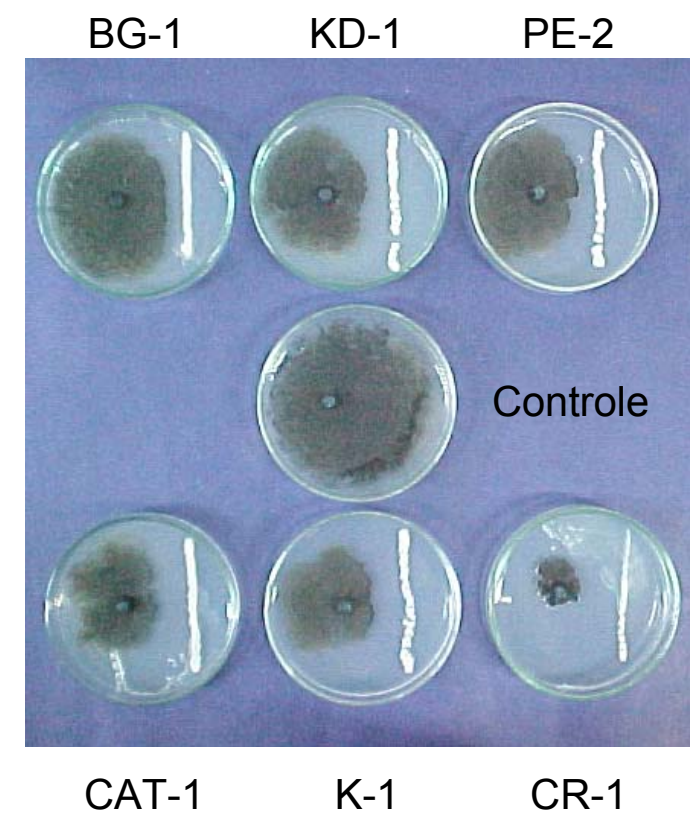

Figura 2 - Efeito antagônico in vitro de diferentes linhagens de S. cerevisiae frente a G. citricarpa. Placas após 8 dias de crescimento a $26^{\circ} \mathrm{C}$ sob fotoperíodo de $12 \mathrm{~h}$

\subsection{Produção de compostos voláteis}

Foi verificada a produção de compostos voláteis capazes de inibir o crescimento vegetativo do fitopatógeno. No experimento onde foi feito o estriamento com a levedura, foi constatado que as linhagens CR-1, K-1, BG-1 e PE-2 são as maiores produtoras de voláteis inibidores do crescimento micelial de G. citricarpa, 59, 50, 43 e 41\%, respectivamente. As outras duas linhagens apresentaram efeito intermediário, $23 \%$ de inibição para CAT-1 e 30\% para KD1 (Figura 3). 


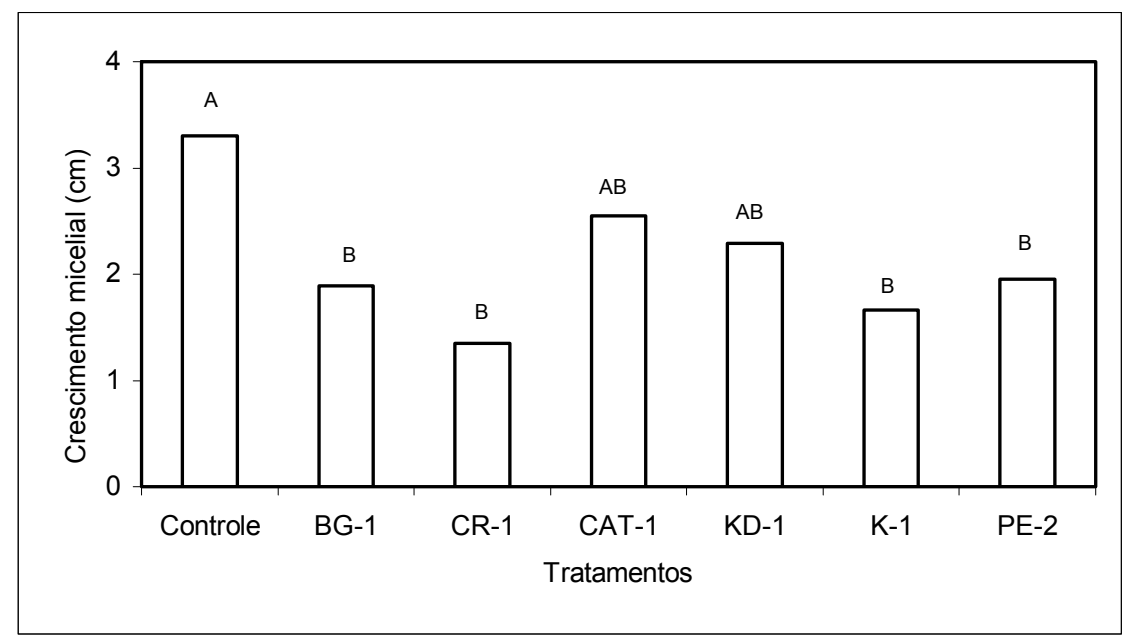

Figura 3 - Efeito de compostos voláteis liberados pelas diferentes linhagens de S. cerevisiae cultivadas através de estriamento no crescimento micelial de G. citricarpa. Médias seguidas pelas mesmas letras não diferem entre si pelo teste de Tukey a $1 \%$

Quando $30 \mu \mathrm{L}$ da suspensão da levedura foi espalhada na superfície do meio, o efeito inibitório foi potencializado e todas as linhagens testadas foram capazes de diminuir o desenvolvimento do fungo, sendo a inibição de 83\% para BG-1 e CR-1, e de 76, 73, 71 e 63\% de inibição para, CAT-1, KD-2, PE-2 e K-1, respectivamente (Figura 4 e 5). 


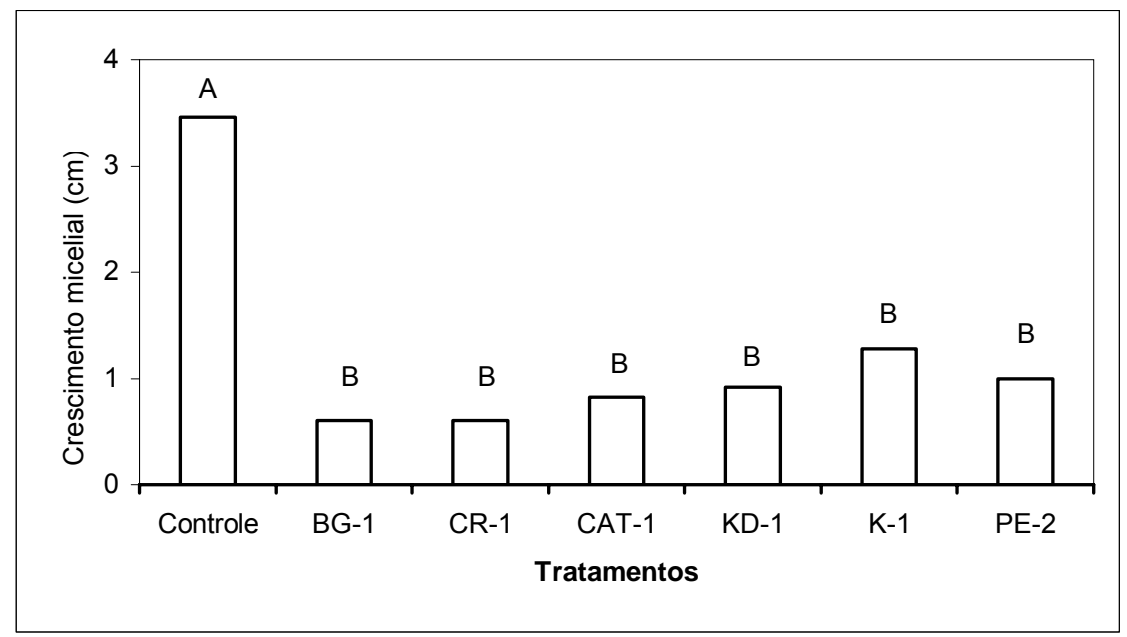

Figura 4 - Efeito de compostos voláteis liberados pelas diferentes linhagens de S. cerevisiae cultivadas através espalhamento sobre superfície no crescimento micelial de G. citricarpa. Médias seguidas pelas mesmas letras não diferem entre si pelo teste de Tukey a 1\%

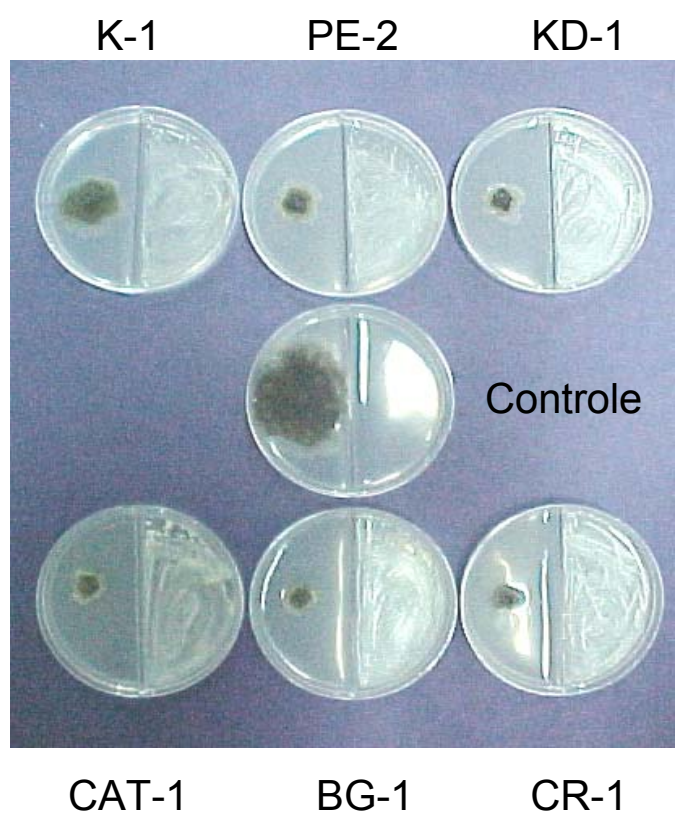

Figura 5 - Efeito de compostos voláteis liberados pelas diferentes linhagens de S. cerevisiae cultivadas através espalhamento sobre superfície no crescimento micelial de G. citricarpa. Placas após 10 dias de crescimento a $26^{\circ} \mathrm{C}$ sob fotoperíodo de $12 \mathrm{~h}$ 
Ao término dos experimentos, os discos de ágar contendo micélio que tiveram o crescimento inibido, retomaram o desenvolvimento normal ao serem transferidos para novas placas contendo meio BDA na ausência do antagonista.

\subsection{Efeito do filtrado de cultura, filtrado de cultura autoclavado e da levedura autoclavada sobre o crescimento micelial de G. citricarpa}

Com base nos experimentos anteriores optou-se por trabalhar com a linhagem CR-1 por ter se mostrado como a melhor antagonista frente ao patógeno. Desta forma, este experimento visou avaliar o efeito de metabólitos produzidos e liberados por esta linhagem de $S$. cerevisiae no meio de cultivo YEPD e capazes de agir no desenvolvimento do fungo fitopatogênico. A Figura 6 mostra que o filtrado do meio de cultivo da levedura obtido a partir do cultivo feito durante $24 \mathrm{~h}$, assim como o meio de cultivo autoclavado e a suspensão de células inativadas termicamente não foram capazes de reduzir o crescimento micelial do patógeno, não diferindo estatisticamente em relação ao tratamento controle (água) ou ao tratamento com o meio YEPD. 


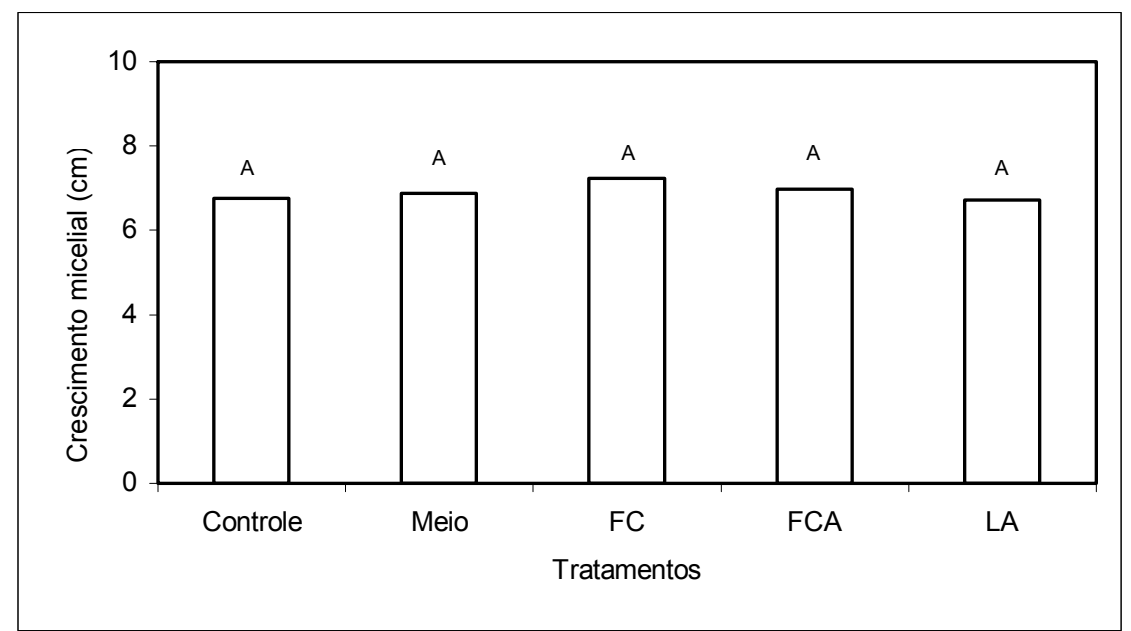

Figura 6 - Efeito de diferentes preparações de S. cerevisiae (linhagem CR-1) sobre o crescimento micelial de G. citricarpa. Controle (água); Meio (YEPD); Filtrado de cultura (FC); Filtrado de cultura autoclavado (FCA) e Levedura autoclavada (LA). Médias seguidas pelas mesmas letras não diferem entre si pelo teste de Tukey a $1 \%$

\subsection{Produção de enzimas hidrolíticas}

No intuito de elucidar os possíveis mecanismos utilizados por $S$. cerevisiae (linhagem CR-1) na atuação como agente antagônico, foi analisada a produção de enzimas hidrolíticas extracelulares (quitinases, $\beta$-1,3-glucanases e proteases), potencialmente capazes de atuar no controle do patógeno. Foram avaliados diferentes tempos de cultivo em meio YEPD e YEPD modificado, ou seja, que continha uma preparação da parede celular (PPC) de G. citricarpa a $1 \%$ em substituição a glicose presente na composição original do meio. É possível observar, na Tabela 1, que a levedura não exibiu nenhuma das três atividades enzimáticas em nível detectável pelos ensaios nos tempos de cultivo avaliados e nas duas composições do meio YEPD. 
Tabela 1. Produção de quitinases, $\beta-1,3$-glucanases e proteases em meio de cultivo pela linhagem CR-1 de Saccharomyces cerevisiae

\begin{tabular}{ccccccc}
\hline \multicolumn{5}{c}{ Atividade enzimática (U/mL) } \\
\hline & YEPD & \multicolumn{4}{c}{ YEPD modificado (PPC 1\%) } \\
Tempo (h) & Quitinase & Glucanase & Protease & Quitinase & Glucanase & Protease \\
12 & ND & ND & ND & ND & ND & ND \\
24 & ND & ND & ND & ND & ND & ND \\
36 & ND & ND & ND & ND & ND & ND \\
48 & ND & ND & ND & ND & ND & ND \\
60 & ND & ND & ND & ND & ND & ND \\
\hline
\end{tabular}

ND: Não detectada 


\section{DISCUSSÃo}

Foram avaliadas seis linhagens de S. cerevisiae (BG-1, CR-1, CAT-1, KD-1, K-1 e PE-2) utilizadas em processos fermentativos, quanto à capacidade de inibir o desenvolvimento de G. citriticarpa in vitro. O fitopatógeno mostrou-se resistente à linhagem BG-1, porém o crescimento micelial foi significativamente reduzido na presença da estria das linhagens KD-1 e PE-1 que promoveram inibição intermediária, enquanto que as linhagens CR-1, CAT-1 e K-1 mostraram ser antagonistas mais efetivos na interação direta, com destaque para CR-1 que promoveu uma inibição média do crescimento micelial de $73 \%$ (Figura 1). O crescimento vegetativo do fungo, de modo geral, mostrou-se susceptível nas proximidades das colônias da levedura formando uma zona de inibição característica, no entanto, através da análise em microscopia de luz visível, não foram constatadas modificações morfológicas visíveis nas hifas presentes na área inibitória.

Walker et al. (1995) demonstraram atividade inibitória in vitro de 17 isolados de leveduras contra diversos fungos de importância agronômica, ambiental e clínica. Dentre estas, as três linhagens de S. cerevisiae avaliadas tiveram forte ação antagônica contra fungos deterioradores de madeira (Serpula lacrymans, Postia placenta, Lentinus lepideus e Ophiostoma ulmi) e fungos fitopatogênicos (Rhizoctonia solani, Fusarium equiseti, Botrytis fabae e Phytophthora infestans).

As espécies de levedura epífitas isoladas de abacaxi e identificadas como Cryptococcus sp., Cryptococcus albidus, Pichia guilliermondii, Rhodoturula aurantiaca e Rhodoturula glutinis inibiram o crescimento micelial in 
vitro (25-50\%) de Ceratocystis paradoxa, agente causal da podridão negra em abacaxi em pós-colheita e também diminuíram a severidade da doença quando a mistura de leveduras foi aplicada nos frutos (Reyes et al., 2004).

Ensaios em placa, utilizando quatro isolados da levedura Metschnikowia pulcherrima, mostraram redução do crescimento vegetativo de patógenos de maçâs em pós-colheita, sendo a inibição de até 31,3 e 18,8\% para Alternaria sp. e Botrytis cinerea, respectivamente, e 20,8\% para Penicillium expansum e Monilia sp. (Spadaro et al., 2002).

A diferença na capacidade inibitória entre as linhagens avaliadas pode refletir diferenças bioquímicas quanto à capacidade de expressar quantitativamente e qualitativamente metabólitos secundários.

É possível que múltiplas toxinas possam ser produzidas por uma única linhagem de levedura em resposta a diferentes organismos desafiantes (Walker et al., 1995). A diferença na sensibilidade de um fitopatógeno fúngico a uma levedura irá variar de acordo com a natureza individual da toxina e pela existência de receptores presentes na parede celular para a toxina em questão (Walker et al., 1995). A ligação da toxina ao receptor desencadeia uma modificação no gradiente eletroquímico de prótons através da membrana plasmática (Santos \& Marquina, 2004).

Bostian et al. (1984) obtiveram a seqüência do plasmídio de RNA que codifica a toxina $\mathrm{K} 1 \mathrm{em} \mathrm{S}$. cerevisiae, uma proteína de $20 \mathrm{kDa}$. O DNA plamidial de Kluyveromyces lactis codifica uma toxina que apresenta subunidades de 90, 30 e 27,5 kDa (Starck et al., 1990). Pichia anomala produz uma toxina de 83,3 kDa (Sawant, et al., 1989). A toxina purificada de Pichia membranifaciens CYC 1106 de massa molecular aparente de $18 \mathrm{kDa}$ exibiu efeito fungicida contra $B$. cinerea em videiras (Santos \& Marquina, 2004).

Foi evidenciado que as leveduras antagonistas são capazes de liberar compostos voláteis inibidores do desenvolvimento do patógeno. Através da Figura 3 é possível observar a sensibilidade de G. citricarpa com relação a gases liberados pelas diferentes linhagens. É possível notar que o perfil de 
inibição é semelhante ao ocorrido no ensaio de antagonismo direto (Figura 1). Desta forma pode-se supor que a produção de voláteis é um fator importante na redução do desenvolvimento fúngico. Quando a concentração de células utilizadas foi aumentada, ou seja, espalhamento da suspensão celular sobre a superfície do meio ao invés do estriamento, notou-se que a inibição foi potencializada, provavelmente pelo maior número de células presentes capazes de produzir compostos voláteis e deste modo proporcionou maior saturação gasosa no ambiente da placa e conseqüentemente a inibição foi maior, e estatisticamente semelhantes para as seis linhagens (Figura 4). Enquanto o ensaio utilizando estriamento desencadeou inibição máxima de 59\% (CR-1), a utilização de espalhamento em superfície proporcionou uma inibição de $83 \%$ (CR-1 e BG-1).

Bruce et al. (2003) verificaram que compostos voláteis produzidos por S. cerevisiae em meio triptona de soja foram capazes de inibir o crescimento de fungos que atacam madeira Sclerophoma pithyophila (75\%), Ophiostoma piliferum (76\%), O. piceae (56\%), Botrydiplodia theobromae $(45 \%)$ e Aureobasidium pullulans (33\%). Segundo os autores, a produção de voláteis é fortemente influenciada pelas condições nutricionais do meio de cultivo utilizado, pois em meio de malte e em meio pobre em nutrientes esta inibição foi de modo geral muito baixa ou nula. Em um trabalho subseqüente, Bruce et al. (2004) identificaram os principais voláteis inibidores produzidos por $S$. cerevisiae como sendo 2-pentanona, dimetil-sulfeto e trimetil-sulfeto.

A produção de metabólitos voláteis, tal como acetato de etila foi relatada no caso de Pichia anomala (Björnberg \& Schnürer, 1993). A ação desse produto é importante para o manejo das doenças, pois inibe 0 crescimento e a germinação de esporos de fungos fitopatogênicos diminuindo a sua sobrevivência (Valdebenito-Sanhueza, 2000).

Muito pouco é conhecido sobre o modo de ação de voláteis microbianos no controle de fungos. Humphris et al. (2002) evidenciaram que 
voláteis produzidos por Trichoderma tiveram efeito sobre a regulação de proteínas específicas em Serpula lacrymans.

A inibição também pode ser atribuída à produção de dióxido de carbono. As leveduras podem utilizar a glicose presente no meio BDA como fonte de carbono e através da respiração produzir energia, água e liberar $\mathrm{CO}_{2}$ $\left(\mathrm{C}_{6} \mathrm{H}_{12} \mathrm{O}_{6}+6 \mathrm{O}_{2} \rightarrow 677,2 \mathrm{cal}+6 \mathrm{H}_{2} \mathrm{O}+6 \mathrm{CO}_{2}\right)$. Experimentos utilizando atmosfera modificada indicaram que concentrações entre 8 e $12 \%$ de $\mathrm{CO}_{2}$ propiciam inibição do crescimento micelial em placa dos fungos de pós-colheita Pestalotiopsis sp., Rhizopus stolonifer e Alternaria alternata (Cia et al., 2003). Análises através de cromatografia gasosa e espectrofotometria de massa devem ser realizados no intuito de identificar a natureza química e concentração dos voláteis inibidores produzidos pela levedura.

Outro mecanismo que poderia estar envolvido no controle de $G$. citricarpa é a produção de enzimas hidrolíticas extracelulares. No entanto, ensaios enzimáticos para quitinases, $\beta$-1,3-glucanases e proteases, utilizando o filtrado de cultura da linhagem CR-1, cultivada em meio YEPD e YEPD contendo preparação de parede celular por períodos de 12, 24, 48 e 60 h, não indicaram produção detectável destas enzimas (Tabela 1). Tal resultado pode estar relacionado a fatores como meio de cultura, tempo e temperatura de cultivo, natureza da linhagem avaliada ou mesmo às condições empregadas nos ensaios enzimáticos.

Sabe-se que S. cerevisiae contém um amplo espectro de endo e exo1,3- $\beta$-glucanases codificadas por aproximadamente 15 genes (Baladrón et al., 2002). Em contraste, possui apenas dois genes codificantes de quitinases, CTS1 e CTS2 (Adams, 2004) que devem estar mais relacionadas ao rearranjo da parede celular durante o crescimento e reprodução.

Saligkarias et al. (2002) estudaram a produção de glucanases e quitinases produzidas pelas leveduras Candida guilliermondii e $C$. oleophila utilizadas no biocontrole de B. cinerea em tomate. Quando cultivadas por $120 \mathrm{~h}$ a $25{ }^{\circ} \mathrm{C}$ em meio de Vogel suplementado com glicose, laminarina ou 
preparação de parede celular do patógeno, houve produção das enzimas independente da fonte de carbono utilizada, no entanto, a produção pareceu ser induzida pela glicose e mais elevada no meio contendo esse monossacarídio.

Tilletiopsis ssp. que demonstram atividade antagônica contra oídios, produzem os maiores níveis de glucanases e quitinases após 21 dias de cultivo (Urquhart \& Punja, 2002). O antagonista Pichia anomala mostrou ser um grande produtor de $\beta$-1,3-glucanase, a qual induziu lise da ponta de hifas entre outras deformações no micélio de $B$. cinerea. A produção é mais elevada depois de 72 $\mathrm{h}$ de incubação em meio contendo parede celular fúngica do que em meio suplementado com glicose (Jijakli \& Lepoivre, 1998). Para muitos fungos a produção de $\beta$-1,3-glucanases sofre repressão catabólica da glicose, principalmente quando utilizada como única fonte de carbono (Pitson et al., 1997). Por sua vez, a produção de proteases por parte de organismos antagonistas tem sido demonstrada in vitro e in vivo como sendo um importante fator contra fitopatógenos (Flores et al., 1997).

Os resultados obtidos indicam, portanto, que a produção e excreção de enzimas hidrolíticas pela linhagem CR-1 de $S$. cerevisiae, não foi detectada nas condições de cultivo empregadas. Tal resultado também poderia ser atribuído às condições inerentes ao ensaio enzimático empregado como $\mathrm{pH}$, temperatura, tempo de reação, entre outros fatores.

O filtrado de cultura obtido a partir do cultivo de S. cerevisiae linhagem CR-1 durante $24 \mathrm{~h}$ não promoveu inibição do fitopatógeno, tão pouco o filtrado de cultura autoclavado e as células inativadas foram efetivas (Figura 6). Com relação à falta de atividade do filtrado de cultura, é possível supor que as condições de cultivo como tempo e meio poderiam não ser adequados para a produção de algum fator inibidor do crescimento fúngico que teria sido produzido e atuado no ensaio em placa. A produção de enzimas e excreção para o meio de cultura não ocorreu nos períodos de tempos avaliados (Tabela 
1), desta forma é possível que enzimas potencialmente atuantes sobre o patógeno estejam presentes no meio em períodos de tempo bem superiores.

Diversos gêneros de leveduras são capazes de produzir e excretar toxinas capazes de eliminar indivíduos da mesma cepa, porém que não apresentam o mesmo fenótipo "killer", além de outros microrganismos não relacionados. As indústrias de alimentos e bebidas foram as primeiras a explorar a habilidade das leveduras em produzir toxinas para matar microrganismos contaminantes (Javadekar et al., 1995).

Caso a levedura seja capaz de produzir e excretar toxinas para o meio de cultivo, estas poderiam ter perdido a sua atividade inibitória neste ensaio, já que a produção e estabilidade de todas as toxinas produzidas por leveduras são fortemente influenciadas pelas condições ambientais. As toxinas são de natureza protéica ou glicoprotéica, ativas em $\mathrm{pH}$ ácido e sensíveis a temperatura e ação de proteases (Woods \& Bevan, 1968; Santos \& Marquina, 2004). Woods \& Bevan (1968) verificaram que a toxina produzida por $S$. cerevisiae é uma proteína extracelular sensível ao calor e ação de proteases. $\mathrm{O}$ $\mathrm{pH}$ ótimo para produção e estabilidade da toxina em meio líquido esteve na faixa entre 4,6 e 4,8 a $22{ }^{\circ} \mathrm{C}$. O chamado fator "killer" foi inativado em temperaturas superiores a $25^{\circ} \mathrm{C}$, em meio líquido, e em temperaturas inferiores a $42{ }^{\circ} \mathrm{C}$, em meio sólido. $\mathrm{O}$ efeito "killer" também foi inativado pela filtração e agitação intensa.

A toxina presente nos filtrados de cultura de $P$. membranifaciens exerceu efeito fungicida sobre $B$. cinerea. $O$ tratamento das plantas com a toxina purificada preveniu a infecção e o surgimento dos sintomas. Em pH 4,0 a atividade inibitória ótima ocorreu a $20^{\circ} \mathrm{C}$ e a $25^{\circ} \mathrm{C}$ o efeito tóxico foi reduzido em $70 \%$. A atividade foi fracamente detectada em pH 6,0 (Santos \& Marquina, 2004).

A partir das informações obtidas é possível supor que a linhagem CR-1 de S. cerevisiae atue sobre G. citricarpa através da produção de compostos voláteis. Além disso, é provável que haja competição por nutrientes e espaço, 
mecanismo este que é o mais apontado por diversos autores como utilizado por leveduras antagonistas no controle de fitopatógenos (Droby et al., 1989; Roberts, 1990; Elad et al., 1994; Cheah et al., 1995b; Piano et al., 1997; Filonow et al., 1998; Saligkarias et al., 2002; Vero et al., 2002; Spadaro et al., 2002).

De modo geral, as leveduras não são produtoras de antibióticos ou outros metabólitos secundários tóxicos (Droby et al., 1991), o que é uma característica interessante no controle de doenças de pós-colheita, já que o consumo de frutos contaminados com antibióticos não é desejável.

Outra vantagem da utilização de S. cerevisiae no controle de doenças é a melhor aceitação por parte dos consumidores, que têm maior familiaridade com o organismo, que é bem conhecido pelo público em geral por ser utilizado na produção de alimentos e bebidas.

Os ensaios in vitro demonstraram o potencial de S. cerevisiae no biocontrole do fitopatógeno $G$. citricarpa, agente causal da pinta preta dos citros. Desta forma, o trabalho proporciona subsídios para estudos in vivo no intuito de se avaliar a efetividade e viabilidade no controle da doença nos frutos de laranja em pós-colheita. 


\section{CONCLUSÕES}

A linhagem CR-1 de $S$. cerevisiae mostrou maior capacidade antagônica frente a G. citricarpa.

Os isolados de $S$. cerevisiae produzem compostos voláteis de ação fungistática que inibem o crescimento micelial do fitopatógeno, porém a ocorrência de outros mecanismos não pode ser descartada.

A produção de enzimas hidrolíticas extracelulares, potencialmente capazes de agir no processo antagônico, não foram detectadas nas condições de ensaio empregadas no estudo.

O filtrado de cultura, filtrado de cultura autoclavado e a levedura inativada termicamente não tiveram efeito sobre 0 desenvolvimento do fitopatógeno. 


\section{REFERÊNCIAS BIBLIOGRÁFICAS}

ABELES, F.B.; FORRENCE, L.E. Temporal and hormonal control of $\beta-1,3$ glucanase in Phaseolus vulgaris. Plant Physiology, v.45, p.395-400, 1970.

ADAMS, D.J. Fungal cell wall chitinases and glucanases, Microbiology, v.150, p.2029-2035, 2004.

AGRIOS, G.N. Plant pathology. 4.ed. San Diego: Academic Press, 1997. $635 p$.

AGUILAR-VILDOSO, C.I. (Coord.). Manual técnico de procedimentos da mancha preta dos citros. Brasília: MAPA/DAS/DDIV, 2002. 72p.

ALCOBA, N.J.; VIGIANI, A.R.; VEJARANO, N.V.; SLVARES, E.E; SERRANO, M.A.; BONILLO, M.C. Mancha negra de los citros: epidemiología y control. San Salvador de Jujuy: Ediciones Universidad Nacional de Jujuy, 2000. 56p.

AVIS, T.J.; BÉLANGER, R.R. Specificity and mode of action of the antifungal fatty acid cis-9-heptadecenoic acid produced by Pseudozyma flocculosa. Applied and Environmental Microbiology, v.67, p.956-960, 2001.

BAEK, J.M.; CHARLES, R; CHARLES, M. The role of extracellular chitinase from Trichoderma virens Gv 29-8 in the biocontrol of Rhizoctonia solani. Current Genetics, v.35, p.41-50, 1999. 
BAKER, K.F.; COOK, R.J. Biological control of plant pathogens. San Francisco: W.F. Freeman, 1974. 433p

BALADRÓN, V.; UFANO, S.; DUEÑAS, E.; MARTÍN-CUADRADO, A.B.; DEL REY, F.; VÁZQUEZ DE ALDANA, C.R. Eng1p, an endo-1,3- $\beta$-glucanase localized at the daughter side of the septum, is involved in cell separation in Saccharomyces cerevisiae. Eukaryot Cell, v.1, p.774-786, 2002.

BALDASSARI, R.B.; GÓES, A. de; SANTOS, J.M.; TIMOSSI, A.J. Microscopia eletrônica de varredura de isolados de Guignardia citricarpa obtidos de plantas cítricas. Summa Phytopathologica, v.27, p.88-92, 2001.

BAPTISTA, A.S. Saccharomyces cerevisiae em milho armazenado e o efeito na redução de aflatoxicoses. Piracicaba, 2001. 94p. Dissertação (Mestrado) Escola Superior de Agricultura "Luiz de Queiroz", Universidade de São Paulo.

BARTLETT, D.W.; CLOUGH, J.M.; GODWIN, J.R.; HALL, A.A.; HAMER, M, PARR-DOBRZANSKI, B. The strobilurin fungicides. Pest Management Science, v.58, p.649-662, 2002.

BENHAMOU, N. Elicitor-induced plant defense pathways. Trends in Plant Science, v.7, p.233-240, 1996.

BENHAMOU, N.; CHET, I. Cellular and molecular mechanisms involved in the interaction between Trichoderma harzianum and Pythium ultimum. Applied and Environmental Microbiology, v.63, p.2095-2099, 1997. 
BENHAMOU, N.; REY, P; CHERIF, M; HOCKENHULL, J.; TIRILLY, Y. Treatment with the mycoparasite Pythium oligandrum triggers induction of defense-related reactions in tomato roots when challenged with Fusarium oxysporum f.sp. radicis-lycopersici. Phytopathology, v.87, p.108-122, 1997.

BETTIOL, W.; GHINI, R. Controle biológico In: BERGAMIN FILHO, A.; KIMATI, H.; AMORIM, L. (Ed.). Manual de fitopatologia: princípios e conceitos. São Paulo: Agronômica Ceres, 1995. v.1, cap.36, p.717-728.

BJÖRNBERG, A.; SCHNÜRER, J. inhibition of the growth of grain-storage molds in vitro by the yeast Pichia anomala (Harsen) Kurtzman. Canadian Journal of Microbiology, v.39, p.623-628, 1993.

BOSTIAN, K.A.; ELLIOTT, Q.; BUSSEY, H.; BURN, V.; SMITH, A.; TIPPER, D.J. Sequence of the preprotoxin dsRNA gene of type I killer yeast: multiple processing events produce a two component toxin. Cell, v.36, p.741-751, 1984.

BRADFORD, M.M. A rapid and sensitive method for the quantitation of microgram quantities of protein utilizing the principle of protein-dye binding. Analytical Biochemistry, v.72, p.248-257, 1976.

BRUCE, A.; DOUGLAS, S.; SUSAN, V.; RON, E. W. Effect of volatiles from bacteria and yeast on the growth and pigmentation of sapstain fungi. International Biodeterioration \& Biodegradation, v.51, p.101-108, 2003.

BRUCE, A.; VERRALL, S.; HACKETT, C.A.; WHEATLEY, R.E. Identification of volatile organic compounds (VOCs) from bacteria and yeast causing growth inhibition of sapstain fungi. Holzforschung, v.58, p.193-198, 2004. 
BUDGE, S.P.; WHIPPS, J.M. Potential for integrated control of Sclerotinia sclerotiorum in glasshouse lettuce using Coniothyrium minitans and reduced fungicide application. Phytopathology, v.91, p.221-227, 2001.

CARSOLIO, C.; BENHAMOU, N.; HARAN, S.; CORTES, C.; GUTIERREZ, A.; CHET, I.; HERRERA, E.A. Role of the Trichoderma harzianum endochitinase gene, ech42, in mycoparasitism. Applied and Environmental Microbiology, v.65, p.929-935, 1999.

CHEAH, L.H.; HUNT, A.W.; POPAY, A.J. Screening of industrial yeasts for biocontrol of Botrytis storage rot in kiwifruit. In: NEW ZEALAND PLANT PROTECTION CONFERENCE, 47., Waitangi, 1994. Proceedings. Rotorua: New Zealand Plant Protection Society, 1994. p.362-363.

CHEAH, L.H.; MARSHALL, A.P; POPAY, A.J. Biological control of Fusarium storage rot of squash with yeasts. In: NEW ZEALAND PLANT PROTECTION CONFERENCE, 48., Hastings, 1995. Proceedings. Rotorua: New Zealand Plant Protection Society, 1995a. p.337-339.

CHEAH, L.H.; TRAN, T.B; POPAY, A.J. Postharvest biocontrol of Penicillium rot of lemons with industrial yeasts. In: NEW ZEALAND PLANT PROTECTION CONFERENCE, 48., Hastings, 1995. Proceedings. Rotorua: New Zealand Plant Protection Society, 1995b. p.155-157.

CHENG, Y.; MCNALLY, D.J.; LABBE, C.; VOYER, N.; BELZILE, F.; BELANGER, R.R. Insertional mutagenesis of a fungal biocontrol agent leads to discovery of a rare cellobiose lipid with antifungal activity. Applied and Environmental Microbiology, v.69, p.2595-2602, 2003. 
CIA, P.; BENATO, E.A.; SIGRIST, J.M.M; SARANTOPOULOS, C; OLIVEIRA, L.M.; PADULA, M. Efeito da atmosfera modificada, in vitro, sobre o crescimento micelial de patógenos de caqui e no controle da podridão de Rhizopus em caqui 'Fuyu' durante armazenamento prolongado. Summa Phytopathologica, v.29, p.266-274, 2003.

COOK, D.W.M.; LONG, P.G.; GANESH, S.; CHEAH, L.H. Attachment of microbes antagonistic against Botrytis cinerea: biological control and scanning electron microscope studies in vivo. Annals of Applied Biology, v.131, p.503-508, 1997.

COOK, R.J.; BAKKER, K.F. The nature and practice of biological control of plant pathogens. St. Paul: The American Phytopathological Society, 1983. $615 p$.

DOIDGE, E.M. Some diseases of citrus prevalent in South Africa. South African Journal Science, v.26, p.320-325, 1929.

DROBY, S.; CHALUTZ, E.; WILSON, C.L. Antagonistic microorganisms as biological control agents of postharvest diseases of fruits and vegetables. Postharvest News and Information, v.2, p.169-173, 1991.

DROBY, S.; CHALUTZ, E.; WILSON, C.L.; WISNIEWSKI, M. Characterization of the biocontrol activity of Debaryomyces hansenii in the control of Penicillium digitatum on grapefruit. Canadian Journal of Microbiology, v.35, p.794-800, 1989. 
EL GHAOUTH, A.; WILSON, C.L.; WISNIEWSKI, M. Control of postharvest decay of apple fruit with Candida saitoana and induction of defense responses. Phytopathology, v.93, p.344-348, 2003.

ELAD, Y.; KAPAT, A. The role of Trichoderma harzianum protease in the biocontrol of Botrytis cinerea. European Journal of Plant Pathology, v.105, p.177-189, 1999.

ELAD, Y.; KOHL, J.; FOKKEMA, N.J. Control of infection and sporulation of Botrytis cinerea on bean and tomato by saprophytic yeasts. Phytopathology, v.84, p.1193-1200, 1994.

EPARVIER, A.; ALABOUVETTE, C. Use of ELISA and GUS transformed strains to study competition between pathogenic and nonpathogenic Fusarium oxysporum for root colonization. Biocontrol Science and Technology, v.4, p.35-47, 1994.

FEICHTENBERGER, E. Mancha-preta dos citros no Estado de São Paulo. Laranja, v.17, p.93-108, 1996.

FEICHTENBERGER, E.; MÜLLER, G.W.; GUIRADO, N. Doenças dos citros (Citrus spp.). In: KIMATI, H.; AMORIM, L.; BERGAMIN FILHO, A.; CAMARGO, L.E.A.; REZENDE, J.A.M. (Ed.) Manual de fitopatologia: doenças das plantas cultivadas. São Paulo: Ceres, 1997. v.2, p.261-296.

FILONOW, A.B. Role of competition for sugars by yeasts in the biocontrol of gray mold of apple. Biocontrol Science and Technology, v.8, p.243-256, 1998. 
FLORES, A.; CHET, I.; HERRERA-ESTRELLA, A. Improved biocontrol activity of Trichoderma harzianum by overexpression of the proteinaseencoding gene prb1. Current Genetics v.31, p.30-37, 1997.

FUNDECITRUS. Manual técnico sobre pinta preta. Araraquara, 2000. 10p. (Boletim Técnico).

GHINI, R.; KIMATI, H. Resistência de fungos a fungicidas. Jaguariúna: Embrapa Meio Ambiente, 2000. 78p.

GICZEY, G.; KERENYI, Z.; FULOP, L.; HORNOK, L. Expression of cmg1, an exo- $\beta-1,3-$ glucanase gene from Coniothyrium minitans, increases during sclerotial parasitism. Applied and Environmental Microbiology, v.67, p.865-871, 2001.

GÓES, A. de Controle da mancha preta dos frutos cítricos. Laranja, v.9, p.293304, 1998.

GÓES, A. de; FEICHTENBERGER, E. Ocorrência da mancha preta causada por Phyllosticta citricarpa (McAlp) Van der Aa (Guignardia citricarpa Kiely) em pomares cítricos do Estado de São Paulo. Fitopatologia Brasileira, v.18, p.138, 1993. Suplemento. /Apresentado ao 26. Congresso Brasileiro de Fitopatologia, Aracajú, 1993 - Resumo/.

GULLINO M.L.; KUIJPERS L.A.M. Social and political implications of managing plant diseases with restricted fungicides in Europe. Annual Review of Phytopathology, v.32, p.559-579, 1994. 
HARMAN, G.E. Myths and dogmas of biocontrol-changes in perceptions derived from research on Trichoderma harzianum T-22. Plant Disease, v.84, p.377-393, 2000.

HOWELL, C.R. Mechanisms employed by Trichoderma species in the biological control of plant diseases: the history and evolution of current concepts. Plant Disease, v.87, p.4-10, 2003.

HUMPHRIS, S.N.; BRUCE, A.; BUULTJENS, T.E.J.; WHEATLEY, R.E. The effects of volatile secondary metabolites on protein synthesis in Serpula lacrymans. FEMS Microbiology Letters, v.210, p.215-219, 2002.

IPPOLITO, A.; EL GHAOUTH, A.; WILSON, C.L.; WISNIEWSKI, M. Control of postharvest decay of apple fruit by Aureobasidium pullulans and induction of defense responses. Postharvest Biology and Technology, v.19, p.265272, 2000.

JAVADEKAR, V.S.; SIVARAMAN, H.; GOKHALE, D.V. Industrial yeast strain improvement: construction of highly flocculent yeast with a killer character by protoplast fusion. Journal of Industrial Microbiology, v.15, p.94-102, 1995.

JIJAKLI, M.H.; LEPOIVRE, P. Characterization of an exo- $\beta-1,3-$ glucanase produced by Pichia anomala strain K, antagonist of Botrytis cinerea on apples. Phytopathology, v.88, p.335-343, 1998.

KAPAT, A.; ZIMAND, G.; ELAD, Y. Effect of two isolates of Trichoderma harzianum on the activity of hydrolytic enzymes produced by Botrytis cinerea. Physiological and Molecular Plant Pathology, v.52, p.127-137, 1998. 
KIELY, T.B. Preliminary studies on Guignardia citricarpa spp.: the asciegenous stage of Phoma citricarpa McAlp. and its relation to black spot of citrus. Proceedings of the Linnean Society of New South Wales, v.73, p.249-292, 1948.

KLOTZ, L.J. Color handbook of citrus disease. 4.ed. Berkeley: University of California, Division of Agricultural Sciences, 1973. 122p.

KOTZÉ, J.M. Black spot. In: WHITESIDE, J.O. GARNSEY, S.M.; TIMMER, L.W. (Ed.) Compedium of citrus diseases. St. Paul: APS Press, 1988, p. 10-12.

KOTZÉ, J.M. Epidemiology and control of citrus black spot in South Africa. Plant Disease, v.65, n. 12, p.945-950, 1981.

KOTZÉ, J.M. History and epidemiology of Citrus Black Spot in South Africa. In: INTERNATIONAL CITRUS CONGRESS, 8., Sun City, 1996. Proceedings. Sun City: International Society of Citriculture, 1996. p.1296-1299.

LIMA, L.H.C.; MARCO, J.L. de; FELIX, C.R. Enzimas hidrolíticas envolvidas no controle biológico por micoparasitismo. In: MELO, I.S.; AZEVEDO, J.L. (Ed.). Controle biológico. Jaguariúna: Embrapa Meio Ambiente, 2000. v.2, cap.8, p.263-304.

LIMON, M.C.; PINTOR-TORO, J.A.; BENITEZ, T. Increased anti-fungal activity of Trichoderma harzianum transformants that overexpress a $33 \mathrm{kDa}$ chitinase. Phytopathology, v.89, p.254-261, 1999. 
LOPEZ, A.M.Q. Controle alternativo da antracnose causada por Colletothichum graminicola (Ces.) Wils. em sorgo (Sorghum bicolor L. (Moench). Rio Claro, 1991. 203p. Dissertação (Mestrado) - Instituto de Biociências, Universidade Estadual Paulista “Júlio de Mesquita Filho".

LORITO, M.; WOO, S.L.; D'AMBROSIO, M.; HARMAN, G.E.; HAYES, C.K.; KUBICEK, C.P.; SCALA, F. Synergistic interaction between cell wall degrading enzymes and membrane affecting compounds. Molecular Plant Microbe Interactions, v.9, p.206-213, 1996.

LUMSDEN, R.D. Development of Gliocladium virens for damping-off disease control. Canadian Journal of Plant Pathology, v.18, p.463-468, 1996.

MACHADO, K.M.G.; LINARDI, V.R. Production of amylase and beta galactosidase by yeasts. Arquivos de Biologia e Tecnologia, v.33, p.247253, 1990.

MADSEN, A.M.; NEERGAARD, E. Interactions between the mycoparasite Pythium oligandrum and sclerotia of the plant pathogen Sclerotinia sclerotiorum. European Journal of Plant Pathology, v.105, p.761-768, 1999.

MARTINS, E.M.F. Controle da ferrugem do cafeeiro (Hemileia vastatrix) através da indução de resistência. In: BETTIOL, W. (Ed.). Controle biológico de doenças de plantas. Brasília: Embrapa, 1991. cap.24, p.345-363.

MARTINS, E.M.F.; MARIA, A.C. de; GRÜNEWALDT-SÖCKER, G.; MORAES, W.B.C. Changes in the resistance of detached coffee leaves by yeast extract filtrate and heat treatment. Fitopatologia Brasileira, v.11, p.899-909, 1986. 
MATHRE, D.E; COOK, R.J.; CALLAN, N.W. From discovery to use traversing the world of commercializing biocontrol agents for plant disease control. Plant Disease, v.83, p.972-983, 1999.

Mc CORMACK, P.J.; WILDMAN, H.G.; JEFFRIES, P. Production of antibacterial compounds by phylloplanne inhabiting yeasts and yeastilike fungi. Applied and Environmental Microbiology, v.60, p.927-931, 1994.

McLAUGHLIN, R.J., WISNIEWSKI, M.E., WILSON, C.L.; CHALUTZ, E. Effect of inoculum concentration and salt solutions on biological control of postharvest diseases of apple with Candida sp. Phytopathology, v.80, p.456-461, 1990.

McONIE, K.C. The latent occurrence in citrus and others hosts of a Guignardia easiluy confused with $G$. citricarpa, the citrus black spot pathogens. Phytopathology, v.54, p.40-43, 1964.

McONIE, K.C. Germination and infection of citrus by ascopores of Guignardia citricarpa in relation to control of black spot. Phytopathology, v.57, p.743746, 1967.

MELO, I.S. Agentes microbianos de controle de fungos fitopatogênicos. In: MELO, I.S.; AZEVEDO, J.L. (Ed.). Controle biológico. Jaguariúna: Embrapa Meio Ambiente, 1998. v.1, cap.1, p.17-60.

MIGHELI, Q.; GONZALEZ-CANDELAS, L.; DEALESSI, L.; CAMPONOGARA, A.; RAMON-VIDAL, D. Transformants of Trichoderma Iongibrachiatum overexpressing the $\beta-1,4$-endoglucanase gene eg11 show enhanced biocontrol of Pythium ultimum on cucumber. Phytopathology, v.88, p.673-677, 1998. 
MILLER, G.H. Use of dinitrosalicylic acid reagent for determination of reducing sugar. Analytical Chemistry, v.31, p.426-429, 1959.

NARDO, E.A.B. de; CAPALBO, D.M.F. Utilização de agentes microbianos de controle de pragas: mercado, riscos e regulamentações. In: MELO, I.S.; AZEVEDO, J.L. (Ed.). Controle biológico. Jaguariúna: Embrapa Meio Ambiente, 1998. v.1, cap.8, p.231-262.

PASCHOLATI, S.F. Potencial de Saccharomyces cerevisiae e outros agentes bióticos na proteção de plantas contra patógenos. Piracicaba, 1998. 123p. Tese (Livre Docência) - Escola Superior de Agricultura "Luiz de Queiroz", Universidade de São Paulo.

PIANO, S., NEYROTTI, V., MIGHELI, Q.; GULLINO, M.L. Biocontrol capability of Metschnikowia pulcherrima against Botrytis postharvest rot of apple. Postharvest Biology and Technology, v.11, p.131-140, 1997.

PICCININ, E. Uso de Saccharomyces cerevisiae na proteção de plantas de sorgo (Sorghum bicolor), maracujá azedo (Passiflora edulis) e eucalipto (Eucaliptus spp.) contra fitopatógenos fúngicos e bacterianos. Piracicaba, 1995. 107p. Dissertação (Mestrado) - Escola Superior de Agricultura "Luiz de Queiroz", Universidade de São Paulo.

PITSON, S.M.; SEVIOUR, R.J.; MCDOUGALL, B.M. Effect of carbon source on extracellular (1-3)- and (1-6)- $\beta$-glucanase production by Acremonium persicinum. Canadian Journal of Microbiology, v.43, p.432-439, 1997. 
PUNJA, Z.K. Genetic engineering of plants to enhance resistance to fungal pathogens - a review of progress and future prospects. Canadian Journal of Plant Pathology, v.23, p. 216-235, 2001.

PUNJA, Z.K.; UTKHEDE, R.S. Using fungi and yeasts to manage vegetable crop diseases. Trends in Biotechnology, v.21, p.400-407, 2003.

RAGSDALE, N.N.; SISLER H.D. Social and political implications of managing plant diseases with decreased availability of fungicides in the United States. Annual Review of Phytopathology, v.32, p.545-557, 1994.

REYES, M.E.Q.; ROHRBACH, K.G.; PAULL, R.E. Microbial antagonists control postharvest black rot of pineapple fruit. Postharvest Biology and Technology, v.33, p.193-203, 2004.

ROBBS, C.F. A mancha preta dos frutos cítricos (Phyllosticta citricarpa): ameaça à citricultura paulista. Laranja, v.11, p.87-95, 1990.

ROBBS, C.F.; BITTENCOURT, A.M. A mancha preta dos frutos: um dos fatores limitantes à produção citrícola do Estado do Rio de Janeiro. Guaratiba: EMBRAPA/CTAt, 1995, 5p. (Comunicado Técnico, 19).

ROBBS, C.F.; PIMENTEL, J.P.; RIBEIRO, R.L. A mancha preta dos citros causada por Phoma citricarpa. Fitopatologia Brasileira, v.15, p.455, 1980. Suplemento. /Apresentado ao 13. Congresso de Fitopatologia, Rio de Janeiro, 1980 - Resumo/. 
ROBBS, C.F.; PIMENTEL, J.P.; RIBEIRO, R.L. A mancha preta dos citros: indentificação da forma perfeita Guignardia citricarpa no Estado do Rio de Janeiro. Fitopatologia Brasileira, v.10, p.248, 1985. Suplemento./Apresentado ao 18. Congresso Brasileiro de Fitopatologia, Fortaleza, 1985 - Resumo/.

ROBERTS, R.G. Postharvest biological control of gray mold of apple by Cryptococcus laurentii. Phytopathology, v.80, p.526-530, 1990.

RODOV, V.; BEN-YEHOSHUA, S.; FANG, D.; D'HALLEWIN, G.; CASTIA, T. Accumulation of phytoalexins scoparone and scopoletin in citrus fruits subjected to various postharvest treatments. Acta Horticulturae, Natural Phenols in Plant Resistance, v.381, p.517-523, 1994.

ROTEM, Y.; YARDEN, O.; SZTEJNBERG, A. The mycoparasite Ampelomyces quisqualis expresses exgA encoding an exo- $\beta-1,3-g l u c a n a s e$ in culture and during mycoparasitism. Phytopathology, v.89, p.631-638, 1999.

SALIGKARIAS, I.D.; GRAVANIS, F.T.; EPTONA, H.A.S. Biological control of Botrytis cinerea on tomato plants by the use of epiphytic yeasts Candida guilliermondii strains 101 and US 7 and Candida oleophila strain I-182: II. a study on mode of action Biological Control, v.25, p.151-161, 2002.

SANTOS, A.; MARQUINA, D. Killer toxin of Pichia membranifaciens and its possible use as a biocontrol agent against grey mould disease of grapevine. Microbiology, v.150, p.2527-2534, 2004. 
SAWANT, A.D.; ABDELAL, A.T.; AHEARN, D.G. Purification and characterization of the anti Candida toxin of Pichia anomala WC65. Antimicrobial Agents and Chemotherapy, v.33, p.48-52, 1989.

SCHIRMBOCK, M.; LORITO, M.; WANG, Y.L.; HAYES, C.K.; ARISAN-ATAC, I.; SCALA, F.; HARMAN, G.E.; KUBICEK, C.P. Parallel formation and synergism of hydrolytic enzymes and peptaibol antibiotics, molecular mechanisms involved in the antagonistic action of Trichoderma harzianum against phytopathogenic fungi. Applied and Environmental Microbiology, v.60, p.4364-4370, 1994.

SILVA, S.R. da; PASCHOLATI, S.F. Saccharomyces cerevisiae protects maize plants, under greenhouse conditions, against Colletotrichum graminicola. Journal of Plant Disease and Protection, v.99, p.159-167, 1992.

SILVA, S.R. da; PASCHOLATI, S.F; MORAES, W.B.C. Efeito de Saccharomyces cerevisae sobre Colletotrichum graminicola, agente causal da antracnose em milho. Fitopatologia Brasileira, v.13, p.91, 1988.

SMITH, J.H. A study of the effect of various disease control programs on spore releases of the citrus black spot pathogen Guignardia citricarpa Kiely. In: INTERNATIONAL CITRUS CONGRESS, 8., Sun City, 1996. Proceedings. Sun City: International Society of Citriculture, 1996. p.351-352.

SPADARO, D.; VOLA, R.; PIANO, S.; GULLINO, M.L. Mechanisms of action and efficacy of four isolates of the yeast Metschnikowia pulcherrima active against postharvest pathogens on apples. Postharvest Biology and Technology, v.24, p.123-134, 2002. 
STANGARLIN, J.R.; PASCHOLATI, S.F. Proteção de plântulas de milho pipoca contra Exserohilum turcicum pelo uso de Saccharomyces cerevisiae. Summa Phytopathologica, v.20, p.16-21, 1994.

STARK, M.J.; BOYD, A; MILEHAM, A.J.; ROMANOS, M.A. The plasmid encoded killer system of Kluyveromyces lactis: a review Yeasts, v.6, p.1-29, 1990.

SUTTON, B.C.; WATERSON, J.M. Guignardia citricarpa. Descriptions of pathogenic fungi and bacteria. Guignardia citricarpa. Surrey: Common Wealth Mycological Institute, 1966. 2p.

URQUHART, E.J.; PUNJA, Z.K. Hydrolytic enzymes and antifungal compounds produced by Tilletiopsis species, phyllosphere yeasts that are antagonists of powdery mildew fungi Canadian Journal of Microbiology, v.48, p.219-229, 2002.

VALDEBENITO-SANHUEZA, R.M.V. Leveduras para o biocontrole de fitopatógenos. In: MELO, I.S.; AZEVEDO, J.L. (Ed.). Controle biológico. Jaguariúna: Embrapa Meio Ambiente, 2000. v.3, cap.2, p.41-56.

VERO, S., MONDINO, P., BURGUENO, J., SOUBES, M.; WISNIEWSKI, M. 2002. Characterization of biocontrol activity of two yeast strains from Uruguay against blue mold of apple. Postharvest Biology and Technology, v.26, p.91-98, 2002.

WALKER, G.M.; MCLEOD, A.H.; HODGSON, V.J. Interactions between killer yeasts and pathogenic fungi. FEMS Microbiology Letters, v.127, p.213222, 1995. 
WILSON, C.L.; WISNIEWSKI, M.E. Biological control of postharvest diseases of fruits and vegetables: an emerging technology. Annual Review of Phytopathology, v.27, p.425-441, 1989.

WISNIEWSKI, M.; BILES, C.; DROBY, S.; MCLAUGHLIN, R.; WILSON, C.; CHALUTZ, E. Mode of action of the postharvest biocontrol yeast Pichia guilliermondii I. Characterization of attachment to Botrytis cinerea. Physiological and Molecular Plant Pathology, v.39, p.245-258, 1991.

WOO, S.L.; DONZELLI, B.; SCALA, F.; MACH, R.; HARMAN, G.E.; KUBICEK, C.P.; DEL-SORBO, G.; LORITO, M. Disruption of the ech42 (endochitinaseencoding) gene affects biocontrol activity in Trichoderma harzianum P1. Molecular Plant Microbe Interactions, v.12, p.419-429, 1999.

WOODS, D.R.; BEVAN, E.A. Studies on the nature of the killer factor produced by Saccharomyces cerevisiae. Journal of General Microbiology, v.51, p.115-126, 1968.

ZEILINGER, S; GALHAUP, C; PAYER, K; WOO, S.L.; MACH, R.L.; FEKETE, C.; LORITO, M.; KUBICEK, C.P. Chitinase gene expression during mycoparasitic interactions of Trichoderma harzianum with its host. Fungal Genetics and Biology, v.26, p.131-140, 1999. 